Working Paper/Document de travail 2015-34

\title{
Heterogeneity in the Dynamic Effects of Uncertainty on Investment
}

by Sungje Byun and Soojin Jo 
Bank of Canada Working Paper 2015-34

September 2015

\title{
Heterogeneity in the Dynamic Effects of Uncertainty on Investment
}

by

\author{
Sungje Byun ${ }^{1}$ and Soojin $\mathrm{Jo}^{2}$ \\ 1Economics Department \\ University of California at San Diego \\ s1byun@ucsd.edu \\ ${ }^{2}$ Canadian Economic Analysis Department \\ Bank of Canada \\ Ottawa, Ontario, Canada K1A 0G9 \\ sjo@bankofcanada.ca
}

Bank of Canada working papers are theoretical or empirical works-in-progress on subjects in economics and finance. The views expressed in this paper are those of the authors.

No responsibility for them should be attributed to the Bank of Canada. 


\section{Acknowledgements}

We are very grateful to James D. Hamilton for his helpful comments and suggestions. We thank the participants of the UCSD GSR, macroeconomic lunch seminars, 2013 Midwest Econometrics Group meeting, the Bank of Canada's brown bag lunch seminar, 2014 SNDE conference, 2014 Korean Econometrics Camp, annual KEA-KAEA conference and the seminar series at Santa Clara University, the University of Ottawa and Maryland University. 


\begin{abstract}
How does aggregate profit uncertainty influence investment activity at the firm level? We propose a parsimonious adaptation of a factor-autoregressive conditional heteroscedasticity model to exploit information in a subindustry sales panel for an efficient and tractable estimation of aggregate volatility. The resulting uncertainty measure is then included in an investment forecasting model interacted with firm-specific coefficients. We find that higher profit uncertainty induces firms to lower capital expenditure on average, yet to a considerably different degree: for example, both small and large firms are expected to reduce investment much more than medium-sized firms. This highlights significant and substantial heterogeneity in the uncertainty transmission mechanism.
\end{abstract}

JEL classification: E22, D80, C22, C23

Bank classification: Econometric and statistical methods; International topics; Domestic demand and components

\title{
Résumé
}

Dans quelle mesure l'incertitude agrégée entourant les profits influence-t-elle les décisions d'investissement de l'entreprise? Les auteurs proposent une adaptation parcimonieuse d'un modèle autorégressif conditionnellement hétéroscédastique à facteurs pour exploiter des données sur le chiffre d'affaires d'un panel de sous-secteurs et parvenir à une estimation à la fois efficiente et maniable de la volatilité agrégée. La mesure de l'incertitude ainsi obtenue est ensuite intégrée à un modèle de prévision de l'investissement dans lequel cette variable interagit avec des coefficients propres aux entreprises. Les auteurs constatent qu'une plus grande incertitude à l'égard des profits amène en général les firmes à abaisser leurs dépenses en immobilisations, mais à des degrés très variables selon leur taille: les entreprises petites et grandes limiteraient beaucoup plus leurs investissements que les firmes de taille moyenne, ce qui témoigne de de l'hétérogénéité importante qui caractérise le mécanisme de transmission de l'incertitude.

Classification JEL : E22, D80, C22, C23

Classification de la Banque : Méthodes économétriques et statistiques; Questions internationales; Demande intérieure et composantes 


\section{Non-Technical Summary}

How does uncertainty about aggregate profits influence investment activity? A large body of literature has examined this question, but the findings so far differ greatly regarding the direction of the uncertainty-investment relation. In this paper, we consider the effects of heterogeneity by exploring firm-level data, which opens up the possibility of clearly understanding divergent conclusions in the literature. To this end, we present an investment forecasting model where both the sign and the magnitude of investment adjustment are examined at the firm level. We investigate how each firm changes investment, and then examine how various firm characteristics contribute to the heterogeneous reaction to uncertainty.

Using the Compustat data set of U.S. and Canadian manufacturing firms from 1989Q1 to 2012Q4, we find that profit uncertainty has a significant but small negative effect on average. However, when we examine the firm-level results, substantial heterogeneity is observed across firms: about $28 \%$ of firms in the sample are expected to increase capital investment when uncertainty is high, and the magnitude of investment adjustment varies considerably across firms. Yet, not much difference is found between Canadian and U.S. firms.

Further, we find that both small and large firms are expected to reduce investment more than medium-sized firms. This non-linear effect of uncertainty with respect to firm size has not been documented in the previous literature where the relationship is considered to be linear based on a two-group analysis. Our finding is rather supportive of the idea that the relation between a firm's available funding and investment timing is non-monotonic and non-linear, assuming that size reflects the firm's financial condition. We further evaluate several other firm characteristics, such as the total-liabilities-to-asset ratio and the subindustry classification. Together, our findings allow a consolidated understanding of the various channels presented in theoretical studies, through which uncertainty affects business investment. 


\section{Introduction}

This paper investigates how aggregate profit uncertainty influences investment activities of manufacturing firms, focusing on heterogeneous responses at the firm level. We offer two innovations to the literature on this topic. First, we propose a volatility process called Panel-autoregressive conditional heteroscedasticity (Panel$\mathrm{ARCH}$ ) for an efficient and computationally tractable estimation of aggregate profit uncertainty. Next, we provide new insights into the role of uncertainty in a firm's investment decision: we capture idiosyncratic responses at the firm level in an investment forecasting model where profit uncertainty is augmented through firm-specific coefficients. Taking the two innovations together, we find significant and substantial heterogeneity in the uncertainty transmission mechanism.

A large body of literature is devoted to study the effect of uncertainty on investment, dating back at least to Hartman (1972) and Abel (1983): they find that a mean-preserving increase in price uncertainty raises capital investments under convex adjustment costs. More recently, Sarkar (2000) shows that an increase in uncertainty below a threshold will have a positive impact on investment in a singleproject partial-equilibrium model. On the other hand, Bernanke (1983) and Bloom (2009) find that when facing uncertainty profitability, a firm would postpone an investment decision and wait until the uncertainty resolves, since, otherwise, the installed capital could not be fully recovered when necessary. Caballero (1991) points out that the degree of imperfect competition is a key factor in determining the sign of the uncertainty-investment relationship. Taken as a whole, the earlier literature arrives at divergent conclusions, depending on the key features highlighted in the model.

Our paper takes a slightly different angle: we turn to an individual firm's investment decision under aggregate profit uncertainty, and focus on heterogeneous responses of firms. We investigate both the sign and the magnitude of investment responses to uncertainty at the firm level, and thus propose a potential reconciliation of the conflicting findings in the existing literature at the aggregate level (e.g., Baum et al. (2008), Bloom (2009), and Slade (2013)). Our paper also differs from the previous studies which ex ante attribute a certain firm feature as an underlying cause of heterogeneity (see e.g., Leahy and Whited (1996), Baum et al. (2010) 
and Ghosal and Loungani (2000)). Rather, we let the data speak for the firm-level heterogeneity first and examine how various features are related to the heterogeneity ex post. Hence, we present a detailed picture of the uncertainty transmission mechanism.

We start by proposing an aggregate volatility process that incorporates crosssectional information from disaggregated 2-digit Standard Industrial Classification (SIC) industry-level data. The new process, called a Panel-ARCH model, aims to extract a common driver of cross-sectional variation by jointly modelling individual entities using a factor structure. We pre-impose factor loadings as being inversely proportional to the sales share of each subindustry, and derive a closed-form loglikelihood function that not only expedites the estimation process but also provides more precise parameter estimates for the aggregate volatility process. From this perspective, Panel-ARCH can be viewed as a parsimonious adaptation of the factorARCH models in Diebold and Nerlove (1989) and Engle et al. (1990). Since PanelARCH utilizes cross-sectional information, it is very helpful when applied to the modelling of volatility in macroeconomic variables which, in general, have a short history and are infrequently observed.

Next, we augment the resulting profit uncertainty series in an otherwise conventional investment forecasting model of manufacturing firms. By allowing the profit uncertainty to be interacted with firm-level coefficients, we further investigate the potential linkage between firms' heterogeneous characteristics and their different responses toward aggregate profit uncertainty. The proposed framework is flexible enough to coherently examine the heterogeneity at the firm level as well as the group level. That is, depending on the question of interest, we let each firm react idiosyncratically to uncertainty, or a group of firms respond differently from other groups. Hence, the framework can easily incorporate a number of firm features and grouping criteria to examine potential causes of the heterogeneity. It is also widely applicable to a number of other cases; for instance, it can be used to investigate how the asset holding or loan growth of financial intermediaries changes heterogeneously when aggregate economic uncertainty rises.

We find substantial heterogeneity in capital investments across firms, with an average small negative effect of uncertainty: about $27.7 \%$ of firms in the sample are expected to increase capital investment when uncertainty is high, and the size of 
investment adjustment varies considerably across firms. For instance, both small and large firms are expected to reduce investment more than medium-sized firms. To the best of our knowledge, this has not been documented in the previous literature such as Ghosal and Loungani (2000), where the relationship between size and investment adjustment appears to be rather linear. We further evaluate several firm characteristics that may be relevant to the heterogeneity, such as the totalliabilities-to-asset ratio, and the subindustry classification, and provide a detailed description of the uncertainty transmission mechanism.

The next section presents the Panel-ARCH process for aggregate profit uncertainty. Section 3 introduces an investment capital decision forecasting model capturing heterogeneous effects of uncertainty, and briefly describes the data. The estimation results, with a detailed discussion on heterogeneity in the uncertainty transmission mechanism, are reported in section 4. Section 5 concludes.

\section{Profit Uncertainty and Panel-ARCH}

\subsection{Profit Uncertainty}

While a firm's profitability is determined by several unobservable factors such as consumer taste, wealth, production technology, and prices of inputs and outputs, we use a firm's sales revenue as a proxy of profitability, since it is a fundamental source of a firm's periodic profit. Sales revenue (henceforth sales) is also less likely to be affected by the firm's non-operating activities, such as profits/losses from its subsidiary as well as its financial investment activities. ${ }^{1}$

Instead of fitting a popular univariate volatility model (e.g., generalized ARCH, or GARCH) to aggregate-level sales, we take another approach of examining crosssectional variations at the subindustry level. ${ }^{2}$ The link between aggregate and subindustry-level sales can be found from the following accounting identity. For a total of $J$ subindustries' sales $\left(S_{t}^{j}\right.$ for $\left.j=\{1, \ldots, J\}\right)$ in the economy, an aggregate

\footnotetext{
${ }^{1}$ Ghosal and Loungani (2000) also construct an annual measure of uncertainty from the residual of a sales forecasting equation of large and small firms, defined as 5-year standard deviations of the residuals.

${ }^{2}$ Our classification of industries in this paper is based on the first 2-digit SIC code. The same classification is found in Gilchrist and Himmelberg (1999) when estimating the marginal profitability of capital using a sales-revenue-to-capital ratio.
} 
sales index $\left(S_{t}\right)$ is defined as

$$
S_{t} \equiv \sum_{j=1}^{J} S_{t}^{j}
$$

and its growth rate from $t$ to $t+1$ can be calculated as

$$
g_{t+1} \equiv \frac{S_{t+1}-S_{t}}{S_{t}}=\sum_{j=1}^{J} w_{j, t} \cdot g_{t+1}^{j}
$$

where $w_{j, t} \equiv S_{t}^{j} / \sum_{j=1}^{J} S_{t}^{j}$ is the sales share of the subindustry $j$ in period $t$ and $g_{t+1}^{j}$ is the growth rate of subindustry $j^{\prime} s$ sales from $t$ to $t+1$. Hence, the aggregate sales growth rate is the weighted average of the subindustries' sales growth rates, where the weights are time-varying and predetermined as the $t$ period's sales share. Intuitively speaking, the weights will further imply how much variations in each subindustry contribute to the aggregate-level volatility.

We define aggregate profit uncertainty as the conditional standard deviation which simultaneously drives unexpected changes in all subindustries' profitability. Support for such a common driver can be found in Herskovic et al. (2014), documenting a strong factor structure in volatilities of firms' sales growth. For estimating unforeseen changes, we consider a one-period-ahead sales growth forecasting model for a subindustry $j$ controlling for observable macroeconomic conditions $Z_{t}$ and seasonality $D_{t}$ as

$$
g_{t+1}^{j}=\delta^{j} g_{t}^{j}+\phi^{j \prime} Z_{t}+\psi^{j \prime} D_{t}+u_{j, t+1}
$$

where coefficients $\delta^{j}, \phi^{j}$ and $\psi^{j}$ are allowed to vary across different subindustries for capturing heterogeneity flexibly.

In the following section, we propose a Panel-ARCH model for estimating aggregate profit uncertainty using a set of cross-sectional forecasting errors $u_{j, t+1}$.

\subsection{Panel-ARCH Model}

As the name implies, a Panel-ARCH process builds upon the conventional ARCH model in that the conditional variance is a linear function of past squared errors, to capture temporal dependence such as volatility persistence and clustering. To incorporate cross-sectional variation, we model aggregate volatility as the volatility of a common factor affecting cross-sectional forecasting errors simultaneously. 
Let $f_{t+1}$ be the common factor affecting the levels of cross-sectional forecasting errors simultaneously. Denoting by $\mathcal{F}_{t}$ all observations through $t$, we model aggregate volatility, $\sigma_{t+1}$, as the conditional standard deviation of $f_{t+1}$, i.e., $E\left[f_{t+1}^{2} \mid \mathcal{F}_{t}\right]=$ $\sigma_{t+1}^{2}$ provided by $E\left[f_{t+1} \mid \mathcal{F}_{t}\right]=0$. Denoting by $\eta_{j, t+1}$ subindustry $j^{\prime} s$ idiosyncratic forecasting error, we conjecture that subindustry $j^{\prime} s$ forecasting error $\left(u_{t+1}^{j}\right)$ has a factor structure:

$$
u_{j, t+1}=\lambda_{j, t} \cdot\left(f_{t+1}+\eta_{j, t+1}\right)
$$

where $\lambda_{j, t}$ is a predetermined loading of subindustry $j$ and $\eta_{j, t+1}$ is a martingale difference sequence with

$$
E\left(\eta_{j, t+1}^{2} \mid \mathcal{F}_{t}\right)=\tau^{2}
$$

where $\tau^{2}$ captures the average conditional variance of idiosyncratic forecasting errors.

The above factor structure is similar in spirit to the factor-ARCH models in Diebold and Nerlove (1989) and Engle et al. (1990). We will demonstrate shortly that simple closed-form expressions for both the likelihood function and $\sigma_{t+1}^{2}$ can be derived if we further specify $\lambda_{j, t}$ as

$$
\lambda_{j, t}=\frac{1}{J \cdot w_{j, t}} .
$$

The above restriction implies that the volatility of each subindustry differs from others depending on its sales share in the previous period. More specifically, subindustry $j$ with a below-average share (i.e., $w_{j, t}<1 / J$ ) tends to have large forecasting-error variations, since such a small subindustry is (i) heavily affected by aggregate uncertainty and (ii) more exposed to subindustry-specific uncertainty. In fact, as shown in Figure A3 in Appendix A.2, the correlation coefficients between forecasting errors $\left(u_{j, t+1}\right)$ and sales shares $\left(w_{j, t}\right)$ across subindustries for each quarter are indeed negative for most periods (113 quarters) in the sample (total 123 quarters), supporting the above specification. Furthermore, it ensures that the conditional variance of the weighted forecasting errors across subindustries is equal to the conditional variance of the common factor as

$$
E\left[\left(\sum_{j=1}^{J} w_{j, t} \cdot u_{j, t+1}\right)^{2} \mid \mathcal{F}_{t}\right]=\sigma_{t+1}^{2}
$$


Therefore, the time-varying aggregate profit uncertainty can be estimated from the recursive formulation of the aggregate volatility as follows:

$$
\begin{aligned}
\sigma_{t+1}^{2} & =a_{0}+\sum_{k=1}^{q} a_{k} \cdot u_{t-k+1}^{2} \\
& =a_{0}+\sum_{k=1}^{q} a_{k} \cdot\left(\sum_{j=1}^{J} w_{j, t-k} u_{j, t-k+1}\right)^{2},
\end{aligned}
$$

where $u_{t-k+1} \equiv \sum_{j=1}^{J} w_{j, t-k} u_{j, t-k+1}$ denotes weighted forecasting errors across subindustries.

Let $\Theta \equiv\left[a_{0}, a_{1}, \cdots, a_{q}, \tau\right]$ be a collection of parameters. Denoting by $u_{t+1}$ a $J \times 1$ vector of forecasting errors, the log-likelihood function for jointly modelling forecasting errors of $J$ subindustries for $t=1, \ldots, T$ is

$$
L(\Theta)=-\frac{T}{2} \log 2 \pi-\frac{1}{2} \sum_{t=1}^{T} \log \left|\Omega_{t+1}\right|-\frac{1}{2} \sum_{t=1}^{T} u_{t+1}^{\prime} \Omega_{t+1}^{-1} u_{t+1}
$$

where $\Omega_{t+1}=E\left[u_{t+1} u_{t+1}^{\prime} \mid \mathcal{F}_{t}\right]$ is a $J \times J$ variance-covariance matrix of forecasting errors.

Note that the evaluation of the above log-likelihood function for a large $J$ is generally burdensome, since it requires the determinant calculation and inversion of $J \times J$ matrix $\Omega_{t+1}$ at each point $t$. In contrast, parsimonious specifications in Panel-ARCH provide a tractable approach for overcoming such empirical difficulties associated with a large $J$. As we detail in Appendix A.1, both the determinant and inverse of $\Omega_{t+1}$ can be calculated analytically, since $\Omega_{t+1}$ is a symmetric matrix for all $t$ and we know all elements under conditions (4), (5) and (6). The closed-form log-likelihood function is given as

$$
\begin{aligned}
L(\Theta)= & -\frac{T}{2} \log 2 \pi-T(J-1) \log (\tau)+2 T \log (J) \\
& -\frac{1}{2} \sum_{t=1}^{T} \log \left(\tau^{2}+J \sigma_{t+1}^{2}\right)+\sum_{t=1}^{T} \sum_{j=1}^{J} \log w_{j, t} \\
& -\frac{J^{2}}{2 \tau^{2}} \sum_{t=1}^{T}\left\{\sum_{j=1}^{J}\left(w_{j, t} u_{j, t+1}\right)^{2}-\frac{\sigma_{t+1}^{2}}{\left(\tau^{2}+J \cdot \sigma_{t+1}^{2}\right)} \cdot\left(\sum_{i=1}^{J} w_{j, t} u_{j, t+1}\right)^{2}\right\},
\end{aligned}
$$

with which the evaluation of the log-likelihood function with $J$ subindustries is as 
simple as that of a univariate series.

Our approach of incorporating cross-sectional information for aggregate volatility estimation is inspired by the literature aiming to estimate underlying volatility with higher precision using information from high-frequency data. For example, Dobrev and Szerszen (2010) and Jo (2014) show that an additional volatility indicator from high-frequency data of the same series can help estimate volatility more accurately, when augmented to the volatility estimation step. However, most macroeconomic variables (including sales revenue) are only available at a quarterly frequency and have a relatively short history, ruling out the possibility of improving volatility precision due to high-frequency data. Thus, Panel-ARCH instead makes use of cross-sectional variations with added computational efficiency. In addition, Byun (2014) shows that using the information of cross-sectional dispersion can help improve the accuracy of parameter estimates, and consequently results in more precise estimates of volatility.

Next, we describe our empirical procedure for estimating aggregate profit uncertainty using Panel-ARCH. Using sales series of all firms in the combined quarterly Compustat North America industrial files from 1981Q1 to 2012Q4, we construct a panel of 67 industries' sales revenues by aggregating sales within the same subindustry, and calculate quarterly sales growth rates as well as sales shares for each subindustry $j .{ }^{3}$ With a one-period-ahead sales growth forecasting model in (3), we obtain forecasting errors of each subindustry from a univariate regression of subindustry $j^{\prime} s$ sales growth rate on two macroeconomic variables (i.e., the quarterly GDP growth rate and effective federal funds rate), seasonal dummies, and its lagged sales growth. Then, we estimate Panel-ARCH(1), Panel-ARCH(1) as well as Panel-GARCH(1,1) as an extension of our general framework from 1982Q1 to 2012Q4 (124 quarters). ${ }^{4}$

Table 1 reports maximum likelihood estimation (MLE), asymptotic standard errors and maximized log-likelihoods under three specifications. ${ }^{5}$ When comparing

\footnotetext{
${ }^{3}$ There are 74 subindustries based on the 2-digit SIC code. In our analysis, we exclude seven subindustries whose sales revenues are infinitesimal or do not exist on a continuation basis over the sample period. They are Agricultural Product-Livestock \& Animal Specialties $(\mathrm{SIC} 2=2)$, Forestry $(\mathrm{SIC} 2=8)$, Fishing, Hunting and Trapping (SIC2=9), and other miscellaneous services (SIC2 $=81,84,86,89)$. Their sales revenues range from $0.00001 \%$ to $0.00308 \%$, and account for $0.0063 \%$ as a whole from 1981Q1 to $2012 \mathrm{Q} 4$.

${ }^{4}$ For model parameter estimation, we condition on the first four quarter observations.

${ }^{5}$ We estimate the asymptotic standard errors by numerically approximating second derivatives of the Hessian matrix at the MLE. See Hamilton (1994, 133-48) for more details.
} 
maximized log-likelihoods, we find that the Panel-ARCH(1) is parsimonious yet sufficient to describe the dynamics of profit uncertainty: the p-values for log-likelihood ratio tests are 0.47 for the Panel-ARCH(2) and 0.43 for the Panel-GARCH$(1,1)$. Hence, we use the estimated profit uncertainty from the Panel-ARCH(1) model in the paper. The parameter estimates of the Panel-ARCH(1) imply that the profit uncertainty has persistence $\left(\alpha_{1}\right)$ of 0.2085 and the long-run average $\left(E\left[\sigma_{t}^{2}\right]\right)$ of 12.24. Estimated $\tau$ indicates that average cross-sectional dispersion is approximately $33.67 \%$, which is commonly observed under alternative specifications.

Figure 1 plots the estimated profit uncertainty process with four shaded past National Bureau of Economic Research (NBER) recession periods. The uncertainty series shows frequent fluctuations over time, even though we first remove seasonality from the sales revenue series by including seasonal dummy variables for each subindustry before estimating the sales forecasting model. ${ }^{6}$ The profit uncertainty tended to increase during and after the 2001 recession, and then surged dramatically during the Great Recession. Figure 2 plots the estimated annualized profit uncertainty process along with the widely-used stock market volatility (VIX) for comparison. In general, the profit uncertainty process remains lower, but more volatile than the VIX, with the Great Recession represented as the period of the highest spike in uncertainty by both measures.

Appendix A.2 provides plots of the quarterly aggregate sales revenue index following equation (1) and the quarterly sales growth rate following equation (2).

\section{An Investment Forecasting Model}

We next examine how uncertainty affects the investment activity of individual firms, with estimated aggregate profit uncertainty (denoted as $\sigma_{t+1 \mid t}$ ). In this section, we begin by describing our firm-level data with firm-specific control variables for explaining the investment activity of individual firms. Next, we propose an investment forecasting model where firms' heterogeneous adjustment of investment will be examined.

\footnotetext{
${ }^{6}$ When we regress the estimated profit uncertainty series on four seasonal dummies, we reject the F-test that all seasonal dummies are jointly zero. However, to show that the results of this paper are not driven by the potential seasonality of the uncertainty series, we estimate all models again using a deseasonalized profit uncertainty series, and the results do not change.
} 
We use the manufacturing firms (SIC codes 2000-3999) in the combined quarterly Compustat North America industrial files from 1989Q1 to 2012Q4. ${ }^{7}$ The data set contains the information of the U.S. and Canadian publicly-traded firms. The obtained panel data are highly unbalanced, since only a few firms span the entire sample period while most emerge (or disappear) in the midst of this period. Hence, we construct an unbalanced panel after deleting observations that are missing, highly distressed or likely to be mergers. The final sample contains 219,538 firm-quarter observations for 96 quarters and 5,197 firms, of which Canadian firms comprise about $10 \%$.

Our main variable of interest is the future investment-to-capital-stock ratio of a manufacturing firm $y_{i, t+1}$. In the investment forecasting model, we control for the firm's investment opportunity, internal funding ability and life-cycle behaviour, using sales revenue (sales, $x_{i t}^{1}$ ), cash and cash-equivalent stocks (cash, $x_{i t}^{2}$ ), and the logarithm of total book-valued assets $\left(\right.$ size,$\left.x_{i t}^{3}\right) .{ }^{8}$ These controls are expected to explain the firm's future profitability as well as its capital investment decision. Given trends in variables (capital expenditure, sales and cash), we follow the standard approach in the literature of transforming them into ratios relative to the beginningperiod capital stocks. Lastly, we adjust the total book-valued assets to 2005Q3 U.S. dollars. All variables except size are in percentages. More details on the data can be found in Appendix B.

Table 2 reports the summary statistics along with the definitions of the selected variables for the analysis. It indicates that the quarterly investment rate $\left(y_{i t+1}\right)$ has a mean of $6.3 \%$ with an interquantile range of $4.7 \%$. In general, all variables exhibit a high degree of kurtosis, with the exception of size.

Next, we describe our investment forecasting model, where the profit uncertainty is interacted with firm-specific slope coefficients. Let $y_{i, t+1}$ be the investment-tocapital-stock ratio of a manufacturing firm $i$ for $i=1, \ldots, n$, and let $X_{i, t}$ be a

\footnotetext{
${ }^{7}$ We focus on the manufacturing industry among others, since the capital expenditures of manufacturing firms take the largest share of total capital expenditure, and thus understanding their variations is critical. According to the U.S. Census Bureau's data, the manufacturing industry in the United States comprised about $19.7 \%$ of total capital expenditures in 2000 . The share fell to $15.4 \%$ in 2009 ; however, manufacturing still remains the largest contributor to total capital expenditures.

${ }^{8}$ While the average Tobin's Q had been a popular proxy since Hayashi (1982) for a firm's investment opportunity, we use the sales revenue instead, following Gilchrist and Himmelberg (1999). Since there has been a long-standing consensus regarding the inappropriateness of the average Tobin's Q, earlier Q-based investment regressions were often augmented by various measures of cash flows. See, for example, the literature reviews in Chirinko (1993) and Hubbard (1997).
} 
$5 \times 1$ vector of firm-specific determinants of the future investment: following the investment literature (e.g., Gilchrist and Himmelberg (1999)), we include sales $\left(x_{i t}^{1}\right)$, cash holdings $\left(x_{i t}^{2}\right)$, size $\left(x_{i t}^{3}\right)$, a constant and lagged investment in $X_{i, t}$. In each period $t=1, \ldots, T$, we assume a linear forecasting model:

$$
y_{i, t+1}=X_{i, t}^{\prime} \cdot \beta+\gamma_{i} \cdot \sigma_{t+1 \mid t}+h_{i, t+1},
$$

where $\beta$ is a $5 \times 1$ vector of coefficients that are common across all firms. $h_{i, t+1}$ is an i.i.d idiosyncratic forecasting error with variance $\zeta^{2}$. To make sure that our results are not driven by the business cycle property of uncertainty, we also include the growth rate of real GDP and the federal funds rate to control for changes in the first moment.

The coefficient of our main interest is $\gamma_{i}$, which is unique for each firm $i$ : it quantifies the heterogeneous effects of profit uncertainty on the next period's investment activity. When $\gamma_{i}$ is set to be the same across firms, it simply examines the average effect of uncertainty, with the proposed model devolving to a standard forecasting model. Hence, the proposed framework can provide a detailed picture of changes at the firm level in a coherent manner.

We use three different model specifications to understand the uncertainty transmission mechanism. First, we estimate the above-mentioned investment forecasting model without heterogeneity, assuming identical $\gamma$ across all $i$ 's (i.e., $\gamma_{i}=\bar{\gamma} \forall i$ ). In what follows, we call this the baseline analysis.

Second, we estimate the model with complete firm-level heterogeneity (i.e., $\gamma_{i} \neq$ $\left.\gamma_{j} \forall i \neq j\right)$. Every firm in the sample has its own $\gamma_{i}$, implying that each can respond differently to aggregate-level profit uncertainty. In this specification, we use the Zigzag algorithm applied recursively along with the numerical MLE; in other words, we estimate $\gamma_{i}^{\prime} s$ and other parameters by iterating between a linear projection and the numerical MLE recursively, until convergence. This handles an empirical difficulty arising from the large dimension of $\gamma_{i}$, adding more than 5,000 firm-specific parameters to the estimation.

Third, we group firms based on their common characteristics such as total bookvalue assets (SIZE), total liability ratio (DEBT), and the 2-digit subindustry classification (SIC2), and illustrate differences in responses by including group-specific 
slope coefficients (i.e., $\gamma_{i}=\bar{\gamma}_{J} \forall i \in J$ ). In this way, characteristics closely related to the heterogeneity are highlighted, linking results more closely to economic fundamentals.

\section{Results}

\subsection{Findings from the Baseline Model}

\section{Profit Uncertainty $(\gamma)$}

Column (1) of Table 3 reports coefficient estimates and asymptotic standard errors of the baseline model without heterogeneity. In the baseline model, firms' future capital investments are, on average, slightly negatively related to our measure of aggregate profit uncertainty. A one-unit increase in uncertainty will decrease firms' investment-to-capital ratios by 0.255 percentage points (pp) across all firms, about $4 \%$ of the average quarterly investment growth rate $(6.3 \%)$. Hence, profit uncertainty, on average, slightly dampens the investment-to-capital ratio. The mild average effect of uncertainty may have contributed to divergent empirical findings at the aggregate level, for example, in Bloom (2009) and Choi (2013). The profit uncertainty having peaked in 2008Q4, the result implies that firms' investment decreased by $0.99 \mathrm{pp}$, due to a one-time surge in the uncertainty from 4.98\% (2008Q3) to $8.87 \%$ (2008Q4). Later, when we extend the model to augment both firm-level and group-level heterogeneities, we consistently find that firms on average decrease investment with an increase in profit uncertainty, despite significant and substantial heterogeneity across different entities. ${ }^{9}$

\section{Other Firm-Specific Controls}

\section{Sales $\left(\beta_{1}\right)$}

Sales have been used as a proxy of investment opportunities in the literature, with the advantage of being available for both private and public firms (see Acharya et al. (2007), for example). We find that sales positively affect capital investment,

\footnotetext{
${ }^{9}$ To make sure that our results are not entirely driven by the business cycle property of uncertainty, we re-estimate the investment forecasting model with additional macroeconomic variables such as GDP and credit spreads to control for changes in the first moment. The result, which is available upon request, is robust to the inclusion of such variables.
} 
in line with previous studies such as Asker et al. (2011): to the extent that sales represent a firm's marginal productivity of capital and profit opportunity, it is more likely for a firm with high sales to make capital investment. More specifically, when the sales-to-capital ratio rises by one standard deviation (219.9\%), investment increases by $1.34 \mathrm{pp}$, about $2 \%$ of both the size of its mean and standard deviation.

\section{Cash $\left(\beta_{2}\right)$}

Cash holdings are an internal source of funding, which can be particularly helpful when a firm is financially constrained, as noted in Faulkender and Wang (2006), Pinkowitz et al. (2006) and Denis and Sibilkov (2010). Confirming the previous findings, the model estimates that the cash holdings of a firm are positively related to the investment forecast: firms with high cash holdings have large internal funds supporting future investments. Additionally, to the extent that the cash holdings of a firm reflect profitability, firms with more cash are more profitable, and hence invest more.

\section{Size $\left(\beta_{3}\right)$}

Our baseline specification result shows that the coefficient of size is positive, but not significant for investment forecasting. This may arise due to different dynamics underlying size. First, from the perspective of a firm's life-cycle behaviour, young and thus smaller firms are expected to be more profitable and invest more. However, size represents many other characteristics than just a firm's life cycle. For example, Gilchrist and Himmelberg (1999) consider it to be informative of a firm's financial condition, since it may represent the stability of its ongoing business activity and/or the degree of public information available for an investment project. Larger firms are also likely to have easier access to external financing. ${ }^{10}$ What we find is likely to be the result based on the mixture of various driving forces.

\subsection{Heterogeneity at the Firm Level}

Given the average mild negative effect of profit uncertainty, we now examine heterogeneity across firms in the uncertainty transmission mechanism. In this section, we estimate the most flexible version of an investment forecasting model that allows heterogeneity at the firm level. That is, we let each firm in the sample react

\footnotetext{
${ }^{10}$ Firm size is hence frequently used to split samples, to distinguish between financially constrained and unconstrained firms (see Gertler and Gilchrist (1994) and Carpenter et al. (1998), among others).
} 
differently to uncertainty and estimate the corresponding model using the Zigzag algorithm. Since firm-specific slope coefficients $\left(\gamma_{i}\right.$ 's) may vary across individual firms, this gives heterogeneity the best chance to be influential. Coefficient estimates for other control variables are similar to those in the baseline case (see Column (2) in Table 3) except for that of size, implying that larger firms are now likely to invest more.

With firm-specific slope coefficients, we find significant heterogeneity in the profit uncertainty transmission channel. In order to highlight the firm-level heterogeneity, Figure 3 plots a histogram of $\gamma_{i}$ s' estimates across 5,197 firms. The histogram shows substantial heterogeneity, although the average of the $\gamma_{i}{ }^{\prime}$ s is negative. ${ }^{11}$ About $27.69 \%$ of firms in our sample would respond positively to profit uncertainty by increasing their capital expenditures. Moreover, among firms that are expected to decrease their future capital expenditure, some are much more severely affected by the uncertainty than others.

To better illustrate the observed heterogeneity, the frequency of $\gamma_{i}$ 's in each bin is stacked by firm-size quintiles in different colours in Figure 3. It is clear that the profit uncertainty is transmitted into firms' capital investment decisions by different magnitudes, conditional on their sizes. For instance, investment decisions of the smallest firms (the first quintile) are most negatively affected, while a large proportion of firms in the third and fourth quintiles expand capital expenditures, facing high profit uncertainty. More importantly, the relationship between the effect of uncertainty and firm size is not linear: many firms in the largest size group are also hit harshly and contract investment activities, yet this is not observed in the previous literature such as Ghosal and Loungani (2000), who show that the negative impact of profit uncertainty is substantially greater in industries dominated by small firms, implying a linear relationship between the two.

Next, we stack the bins by quintiles based on firms' total liability ratios in Figure 4. As anticipated, we see that the effect of profit uncertainty is more severe for firms with higher liability ratios. At the same time, a fare share of firms in the top two debt ratio groups are still expected to increase investment. Related to this point, Boyle and Guthrie (2003) show that it can be beneficial for a firm with low future

\footnotetext{
${ }^{11}$ The average of the point estimates of $\gamma_{i}$ 's is -0.325 and the median is -0.260 , consistent with the baseline estimate of $\gamma(-0.255)$ presented in section 4.1 .
} 
liquidity to make an early investment if it considers waiting too risky, as the delayed investment also pertains to elevated uncertainty in future funding availability.

\subsection{Firm Characteristics and Uncertainty}

Here we first group firms based on size, liability ratio, and 2-digit SIC subindustry classification and include corresponding group-specific coefficients of uncertainty in the investment forecasting model. This specification lets heterogeneity be manifested to a lesser degree, yet it makes the interpretation of results easier and presents the heterogeneity in a concise and statistically robust way: the estimation is done by MLE alone in this case, without the necessity of the Zigzag algorithm, affording a chance to evaluate the model formally using likelihood ratio test statistics.

The last three columns in Table 3 report the coefficient estimates for firm-specific controls, which are similar to the preceding two columns except those of the constants barring size. Hence we next discuss in detail how different firm characteristics are related to the heterogeneity, abstaining from other firm-level controls. Table 4 reports estimated parameters for group-level heterogeneity together with brief descriptions of the grouping criteria.

\section{Size}

We first divide firms by size, allocating them into five groups based on their average total assets during the sample period. ${ }^{12}$ Panel 1 of Table 4 reports the number of firms, and the average size in each group. It also presents the estimates for group-specific coefficients of uncertainty. Figure 5, a bar chart of the group-level fixed-effect estimates, illustrates the heterogeneity.

We gain three insights. First, firms of all sizes are anticipated to reduce future capital expenditures when profit uncertainty is high. This is a rather simplified finding from Figure 3, where a fair share of the firms are expected to increase capital expenditure under high uncertainty, when firm-level heterogeneity is allowed. Second, smaller firms are more severely affected by the high profit uncertainty than their larger counterparts. More importantly, however, the relationship between the

\footnotetext{
${ }^{12}$ Since only a few companies span the entire sample, the grouping is based on the firms' average total assets, which are book-valued, denominated in 2005Q3 U.S. dollars and averaged within their presence during the sample periods.
} 
size and the magnitude of response is not linear, but has an inverse U-shape: in fact, firms of the largest size group respond more negatively to profit uncertainty than those of the smallest size group. This is in line with the result from the model in section 4.2 .

It is worth noting, again, that the inverse U-shape relationship between the size and the magnitude of response has not previously been found in the literature, mainly because of a framework that admits only a coarse grouping. For example, Eisner (1978) documents that small firms' timings of investments are more sensitive to profits compared to those of large firms, and Ghosal and Loungani (2000) find that smaller firms are affected more negatively by profit uncertainty. Compared to the earlier approaches, our analysis allows us to have a larger number of groups. The inverse $\mathrm{U}$ relationship is still visible when we increase the number of size groups.

As noted earlier, size has often been thought of as a proxy for financial constraints: small firms are considered more financially constrained than large ones. Our result mirrors this idea to some extent, since smaller firms decrease capital expenditure more when profit uncertainty increases. However, it also shows that size represents other characteristics beyond just financial constraints: for example, size may reflect a degree of monitoring from investors. In addition, larger firms are likely to have a higher capital adjustment cost. Together, these features can result in firms in the largest group being less resilient to uncertainty changes.

\section{Debt}

The leverage ratio (total-assets-to-liabilities ratio) of firms has been extensively used to identify firms with external funding abilities (see Bernanke et al. (1999) for an extensive literature review). For example, Lang et al. (1996) note that high leverage reduces a firm's financing ability to pursue a profitable investment opportunity through a liquidity effect. Using a total-liabilities-to-assets ratio (hereafter, liability ratio) as a proxy for a firm's financing ability, we estimate group-specific slope coefficients of uncertainty.

Panel 2 of Table 4 reports the number of firms and the average liability ratio in each group, followed by $\gamma_{i}$ 's estimates; the results are plotted in Figure 6 . The results show that the profit uncertainty is more detrimental to firms with higher liability ratios, and that the estimated size of the uncertainty effect (in an absolute value) 
increases monotonically. To the extent that the liability ratio reflects marginal costs for external fundings, this suggests that the profit uncertainty is expected to contribute to a firm's investment more strongly for a firm with higher external funding costs. In other words, firms with higher liability ratios will face difficulties in business activities when uncertainty is high, as long as they are more likely to be financially constrained.

\section{Industry}

Finally, we consider the firms' subindustry classification within the manufacturing industry, which is a frequently used grouping criterion in previous studies. Assuming that firms within the same subindustry share common characteristics such as the price elasticity of demand and production technology, we group them based on the first 2-digit SIC code following Gilchrist and Himmelberg (1999). For instance, the SIC code for Texaco Inc. is 2911, with the first two digits, 29, indicating that its core business is related to "petroleum and coal products." The first three columns in Panel 3 of Table 4 provide the 2-digit SIC code, the description of the core businesses and the number of firms within each group.

Subindustry level estimates of $\gamma_{i}$ 's are shown in the last column in Panel 3 of Table 4. They are again substantially different from each other. For instance, the point estimate of "furniture and fixture $(\mathrm{SIC} 2=25)$ " is -0.5426 : this indicates that investment of this industry is expected to decline facing high profit uncertainty. On the contrary, the estimate for "electronic and other electric equipment (SIC2=36)" $(-0.0432)$ states that firms in this industry are rather resilient to uncertainty.

Regarding the subindustry classification, Leahy and Whited (1996) compare the labour-to-capital ratios of subindustries. In particular, they suggest that a higher or more volatile labour-to-capital ratio means a lower capital intensity and thus a higher substitutability of capital by labour. From this perspective, investment activities of firms facing such flexible production technologies would be less affected by profit uncertainty. ${ }^{13}$ However, Leahy and Whited found from empirical analysis that firms with a higher (and more volatile) labour-to-capital ratio would reduce capital investment more, contrary to the prior belief.

\footnotetext{
${ }^{13}$ The assumption that a higher labour-to-capital ratio (or higher volatility of the ratio) can be attributed to an easier substitutability of capital holds when a firm faces a convex return, as noted in Abel (1983).
} 
Following Leahy and Whited (1996), we display the labour-to-capital ratio of subindustries in the year 2000, as well as the historical standard deviation of yearly changes in Panel 3 of Table $4 .^{14}$ Further, Figures 8 and 9 show the group-specific slope coefficients plotted against labour-to-capital ratios and their historical standard deviations, respectively. Both figures show overall negative correlations between $\gamma_{i}$ 's and labour-to-capital ratios (or standard deviations), in line with the empirical findings of Leahy and Whited. ${ }^{15}$

Therefore, our results suggest that the labour-to-capital ratio or its historical variability is not a direct indicator of the labour-capital substitutability and, further, the convexity of the production function. Related to this point, it is possible for an industry to be labour-intensive, although the substitutability between labour and capital is low. For example, a firm within the industry sharing a high labour-to-capital ratio, such as "transportation equipment (SIC 37)," would still have relatively high fixed costs of capital, making it difficult to cope with high profit uncertainty.

\subsection{Uncertainty of Long-Run Horizon}

We so far have examined firms' investment activity using a one-quarter-ahead profit uncertainty measure. As pointed out in Alquist et al. (forthcoming) and Kilian and Vigfusson (2011), however, investment incurring large-scale expenditures may be affected by uncertainty of longer horizons, e.g, one-year-ahead profit uncertainty, rather than its quarterly variation. Therefore, it is a natural extension to see whether the results hold when we instead use profit uncertainty of longer horizons. ${ }^{16}$ In this regard, we extract low-frequency dynamics of our profit uncertainty

\footnotetext{
${ }^{14}$ The historical labour and capital productivity indexes are obtained from the Bureau of Labor Statistics, "Superseded historical SIC measures for manufacturing sectors and 2-digit SIC manufacturing industries, 1949-2001." The labour-to-capital ratio in the year 2000 is used as a representative level, and the historical standard deviation, calculated from yearly log changes, is used as a proxy for a variation for each subindustry.

${ }^{15}$ Although overall negative relations are common to both, our approach has 20 subindustry groups as opposed to the fewer groups (high/low substitutability) of Leahy and Whited (1996). Thus, this paper provides a more detailed picture of the relation.

${ }^{16}$ We appreciate John Campbell's suggestion regarding the importance of the low-frequency movement in future profit uncertainty in firm investment activity.
} 
measure $\left(\bar{\sigma}_{t+1 \mid t}^{2}\right)$ by taking moving averages with five-quarter rolling windows:

$$
\bar{\sigma}_{t+1 \mid t}^{2} \equiv \frac{\sigma_{t-1 \mid t-2}^{2}+\sigma_{t \mid t-1}^{2}+\sigma_{t+1 \mid t}^{2}+\sigma_{t+2 \mid t+1}^{2}+\sigma_{t+3 \mid t+2}^{2}}{5} .
$$

In Figure 10, $\bar{\sigma}_{t+1 \mid t}^{2}$ shows much smoother dynamics, with most short-run fluctuations having disappeared. Table 5 reports estimation results of our baseline model under the alternative measure. Here we also include the result using recursive fourquarter-ahead forecasts of profit uncertainty and the VIX for comparison. ${ }^{17} \mathrm{We}$ find that estimation results are robust under all three alternative measures of the profit uncertainty. ${ }^{18}$

\section{Conclusion}

This paper investigates how time-varying profit uncertainty affects manufacturing firms' business activities, using the Compustat data set from 1989Q1 to 2012Q4 and accounting for heterogeneous investment adjustments across firms. On average, we find that aggregate profit uncertainty affects firms' investment activity slightly negatively, in line with findings in the literature (see Bernanke (1983), Bloom et al. (2007) and Lahiri and Sheng (2010), among others). More importantly, we show significant heterogeneities in the way that firms respond to uncertainty.

One of the main contributions of this paper is to introduce a Panel-ARCH model, which helps more precise and computationally efficient estimation of aggregate profit uncertainty through a factor structure. This is done by pre-selecting factor loadings and idiosyncratic volatilities proportional to an industry's sales share, consistent with the findings in the data. Thus, the Panel-ARCH model adapts the factorARCH model in Diebold and Nerlove (1989) and Engle et al. (1990) in a parsimonious way. The proposed model can be particularly useful when a series of interest is

\footnotetext{
${ }^{17}$ Conditional on information at time $t$, recursively $m$-period-ahead uncertainty forecasts $\left(\sigma_{t+m \mid t}^{2}\right)$ are generated, as $\sigma_{t+m \mid t}^{2}=E\left[\left(\sum_{i=1}^{J} w_{t+m-1}^{j} \cdot u_{t+m}^{j}\right)^{2} \mid \digamma_{t}\right]=\alpha_{0}+\alpha_{1} \cdot \sigma_{t+m-1 \mid t}^{2}$. In particular, we use a four-quarter-ahead forecast of the profit uncertainty, $\sigma_{t+4 \mid t}^{2}$.

${ }^{18}$ Of note is the size of coefficient estimates of profit uncertainty, which increases in absolute terms due to the lower long-run average of those measures. In particular, the four-quarter-ahead uncertainty series generated recursively has a level and magnitude smaller than one-quarter-ahead uncertainty, due to the fact that in an ARCH model the volatility converges to a long-run mean, but the overall dynamics remain the same as before.
} 
only available at a low frequency with a short sample period, yet its subcomponents are attainable, which is the case for most macroeconomic variables.

This paper also provides a framework that can coherently assess heterogeneous adjustments of firms' business investment in responding to changes in profit uncertainty: that is, the profit volatility series is included in an investment forecasting model interacted with firm-specific slope coefficients. As a result, we can analyze potential heterogeneity at the firm or group level, without having to group samples in a certain way a priori, achieving more flexibility compared to previous studies.

Using our framework, we find that firms differ substantially in the way they adjust capital investment in response to aggregate profit uncertainty. We further investigate several firm characteristics attributable to the heterogeneity. For instance, the smallest and largest firms are affected more adversely than medium-sized ones. In addition, a firm's liability ratio can be a factor in determining the size of the uncertainty effect, likely to represent financing constraints. Finally, a firm's production technology, implied by the subindustry classification and labour-to-capital ratio, is related to the size of the uncertainty effect.

\section{References}

Abel, Andrew B. (1983), "Optimal investment under uncertainty." American Economic Review, 73, 228-233.

Acharya, Viral V., Heitor Almeida, and Murillo Campello (2007), "Is cash negative debt? a hedging perspective on corporate financial policies." Journal of Financial Intermediation, 16, 515-554.

Alquist, Ron, Lutz Kilian, and Robert Vigfusson (forthcoming), "Forecasting the price of oil." In Handbook of Economic Forecasting, 2, edited by Graham Elliott and Allan Timmermann, Amsterdam: North-Holland.

Asker, John, Joan Farre-Mensa, and Alexander Ljungqvist (2011), "Comparing the investment behavior of public and private firms." NBER Working Paper No. 17394.

Baum, Christopher F., Mustafa Caglayan, and Oleksandr Talavera (2008), "Uncertainty determinants of firm investment." Economics Letters, 98, 282-287.

Baum, Christopher F., Mustafa Caglayan, and Oleksandr Talavera (2010), "On the sensitivity of firms' investment to cash flow and uncertainty." Oxford Economic Papers, 62, 286-306. 
Bernanke, Ben S. (1983), "Irreversibility, uncertainty, and cyclical investment." Quarterly Journal of Economics, 98, 85-106.

Bernanke, Ben S., Mark Gertler, and Simon Gilchrist (1999), "The financial accelerator in a quantitative business cycle framework." Handbook of Macroeconomics, 1, 1341-1393.

Bloom, Nicholas (2009), "The impact of uncertainty shocks." Econometrica, 77, 623-685.

Bloom, Nicholas, Stephen Bond, and John Van Reenen (2007), "Uncertainty and investment dynamics." Review of Economic Studies, 74, 391-415.

Boyle, Glenn W. and Graeme A. Guthrie (2003), "Investment, uncertainty, and liquidity." Journal of Finance, 58, 2143-2166.

Byun, Sungje (2014), "The usefulness of cross-sectional dispersion for forecasting aggregate stock price volatility." UCSD working paper.

Caballero, Ricardo J. (1991), "On the sign of the investment-uncertainty relationship." American Economic Review, 81, 279-288.

Carpenter, Robert E., Steven M. Fazzari, and Bruce C. Petersen (1998), "Financing constraints and inventory investment: A comparative study with high-frequency panel data." Review of Economics and Statistics, 80, 513-519.

Chirinko, Robert S. (1993), "Business fixed investment spending: Modeling strategies, empirical results, and policy implications." Journal of Economic Literature, 31, 1875-1911.

Choi, Sangyup (2013), "Are the effects of Bloom's uncertainty shocks robust?" Economics Letters, 119, 216-220.

Denis, David J. and Valeriy Sibilkov (2010), "Financial constraints, investment, and the value of cash holdings." Review of Financial Studies, 23, 247-269.

Diebold, Francis X. and Marc Nerlove (1989), "The dynamics of exchange rate volatility: a multivariate latent factor arch model." Journal of Applied Econometrics, 4, 1-21.

Dobrev, Dobrislav and Pawel Szerszen (2010), "The information content of highfrequency data for estimating equity return models and forecasting risk." FRB International Finance Discussion Papers No. 1005.

Eisner, Robert (1978), "Capital expenditure - some further analysis." In Factors in Business Investment, 117-132, NBER.

Engle, Robert F., Victor K. Ng, and Michael Rothschild (1990), "Asset pricing with a factor-arch covariance structure: Empirical estimates for treasury bills." Journal of Econometrics, 45, 213-237.

Faulkender, Michael and Rong Wang (2006), "Corporate financial policy and the value of cash." Journal of Finance, 61, 1957-1990. 
Gertler, Mark and Simon Gilchrist (1994), "Monetary policy, business cycles, and the behavior of small manufacturing firms." Quarterly Journal of Economics, 109, 309-340.

Ghosal, Vivek and Prakash Loungani (2000), "The differential impact of uncertainty on investment in small and large businesses." Review of Economics and Statistics, $82,338-343$.

Gilchrist, Simon and Charles Himmelberg (1999), "Investment: fundamentals and finance." In NBER Macroeconomics Annual 1998, volume 13, 223-274, MIT Press.

Hamilton, James D. (1994), Time Series Analysis, volume 2. Cambridge Univ Press.

Hartman, Richard (1972), "The effects of price and cost uncertainty on investment." Journal of Economic Theory, 5, 258-266.

Hayashi, Fumio (1982), "Tobin's marginal q and average q: A neoclassical interpretation." Econometrica: Journal of the Econometric Society, 213-224.

Herskovic, Bernard, Bryan Kelly, Hanno Lustig, and Stijn Van Nieuwerburgh (2014), "The common factor in idiosyncratic volatility: Quantitative asset pricing implications." Chicago Booth Research Paper.

Hubbard, R. Glenn (1997), "Capital-market imperfections and investment." NBER Working Paper No. 5996.

Jo, Soojin (2014), "The effects of oil price uncertainty on global real economic activity." Journal of Money, Credit and Banking, 46, 1113-1135.

Kilian, Lutz and Robert J. Vigfusson (2011), "Nonlinearities in the oil price-output relationship." Macroeconomic Dynamics, 15, 337-363.

Lahiri, Kajal and Xuguang Sheng (2010), "Measuring forecast uncertainty by disagreement: The missing link." Journal of Applied Econometrics, 25, 514-538.

Lang, Larry, Eli Ofek, and René M. Stulz (1996), "Leverage, investment, and firm growth." Journal of Financial Economics, 40, 3-29.

Leahy, John and Toni Whited (1996), "The effect of uncertainty on investment: Some stylized facts." Journal of Money, Credit and Banking, 28, 64-83.

Pinkowitz, Lee, René Stulz, and Rohan Williamson (2006), "Does the contribution of corporate cash holdings and dividends to firm value depend on governance? A cross-country analysis." Journal of Finance, 61, 2725-2751.

Sarkar, Sudipto (2000), "On the investment-uncertainty relationship in a real options model." Journal of Economic Dynamics and Control, 24, 219-225.

Slade, Margaret E. (2013), "Investment and uncertainty with time to build: Evidence from U.S. copper mining." UBC working paper. 
Figure 1: Aggregate Profit Uncertainty Estimated from a Panel-ARCH(1)

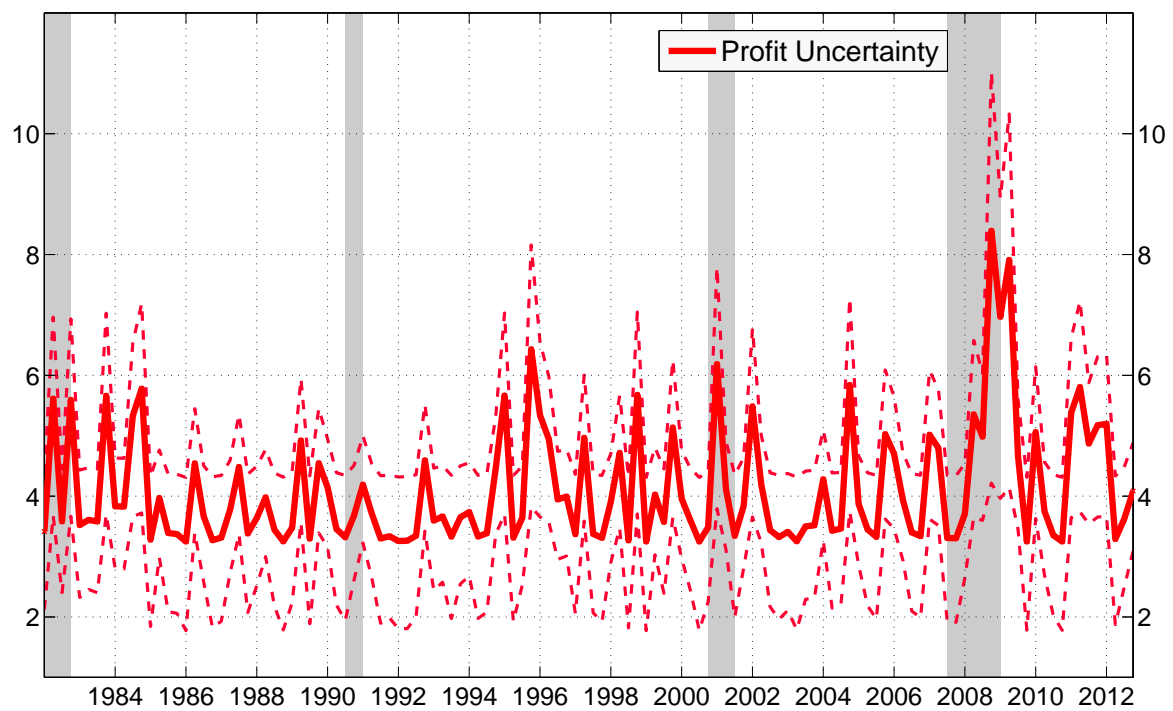

Note: Plotted above is the estimated aggregate profit uncertainty series from the Panel-ARCH(1) model from 1982Q1 to 2012Q4. The dotted lines represent lower and upper bounds for the 95\% confidence band, constructed by simulating the Panel-ARCH(1) model 1,000 times using MLE and the Hessian matrix. Shaded are the NBER recession dates.

Figure 2: Profit Uncertainty and VIX

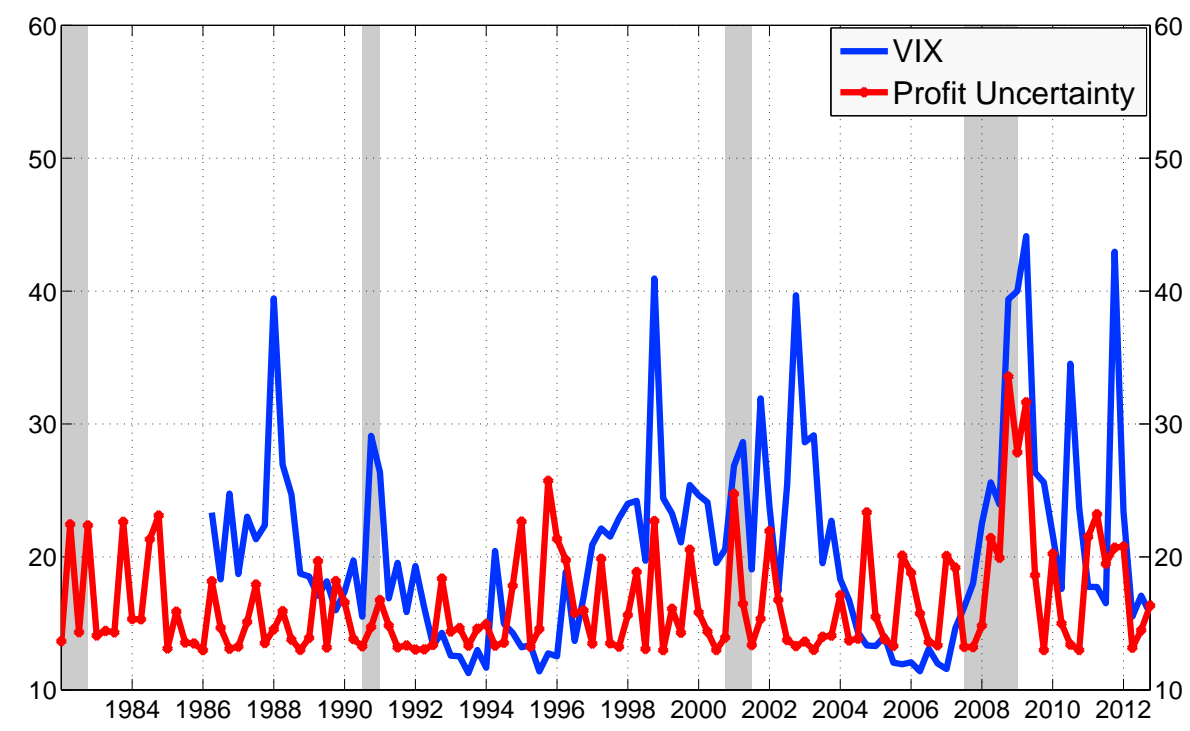

Note: This figure plots the estimated aggregate profit uncertainty and the VIX for the period 1982Q1-2012Q4. The aggregate profit uncertainty is annualized by multiplying 4 for a comparison. Shaded are the NBER recession dates. 
Figure 3: Responses to Uncertainty Grouped by Firm Size

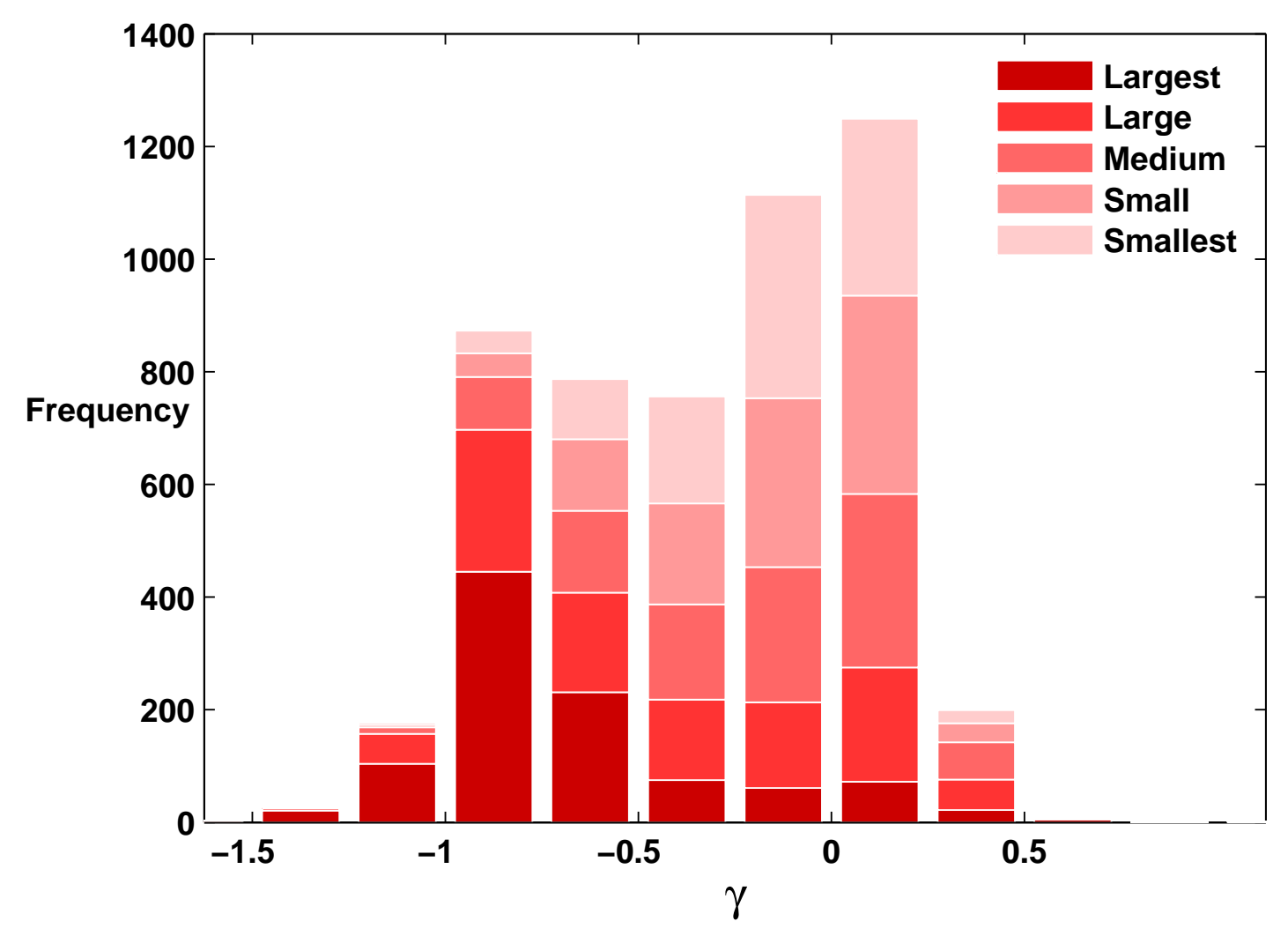

Note: This is a histogram of the estimates of firm-specific slope coefficients $\left(\gamma_{i}\right.$ 's) across 5,197 firms, from the model with complete firm-level heterogeneity: each firm is allowed to respond differently to aggregate profit uncertainty. The bars are colour-coded to represent the size quintile to which a firm belongs. 
Figure 4: Responses to Uncertainty Grouped by Debt Ratio

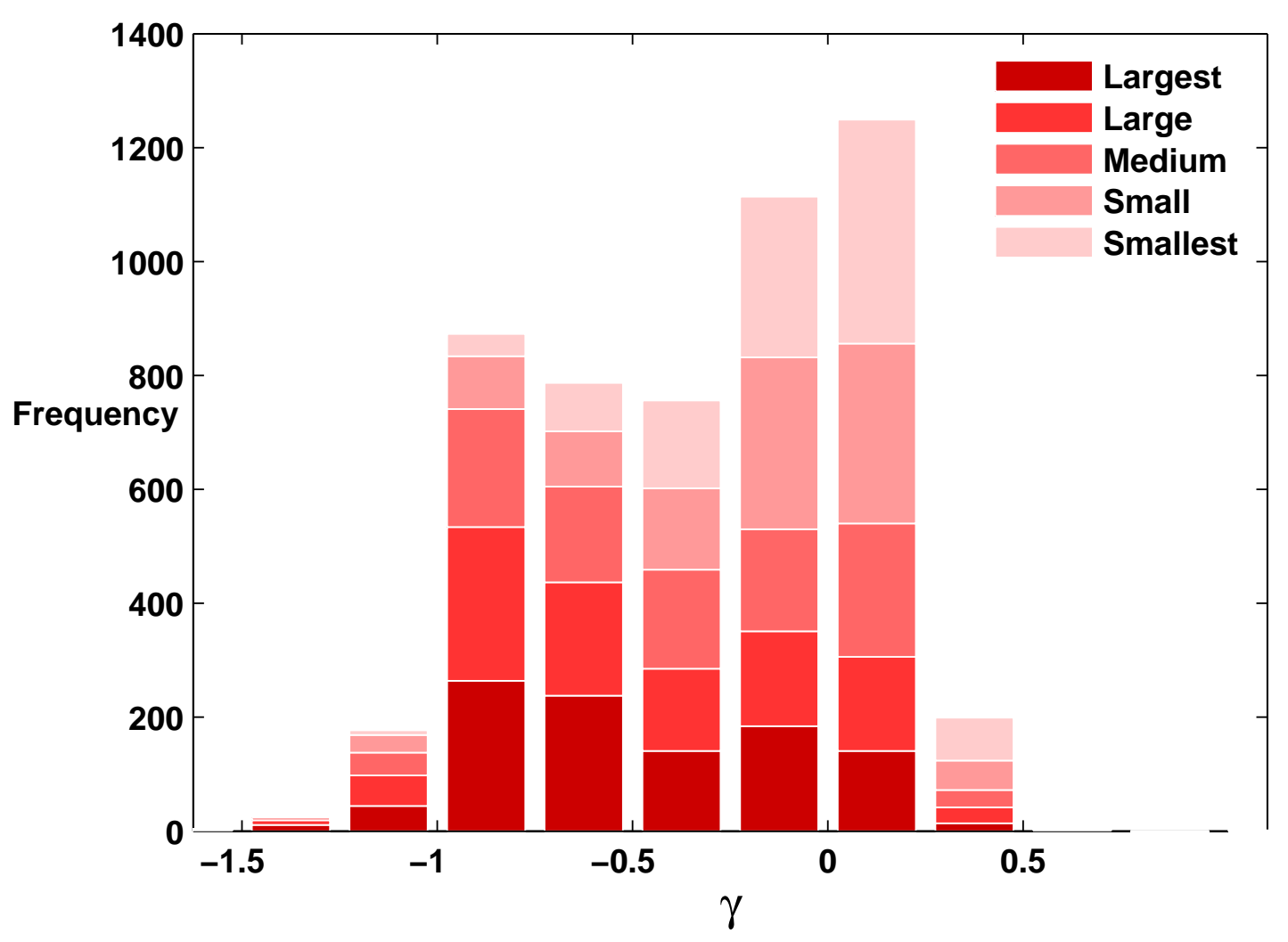

Note: This is a histogram of the estimates of firm-specific slope coefficients $\left(\gamma_{i}\right.$ 's) across 5,197 firms, from the model with complete firm-level heterogeneity: each firm is allowed to respond differently to aggregate profit uncertainty. It is the same histogram as Figure 3, but the bars are colour-coded to represent the quintiles of the total-liabilities-to-asset ratio to which a firm belongs. 
Figure 5: By Firm Size: Responses to Uncertainty

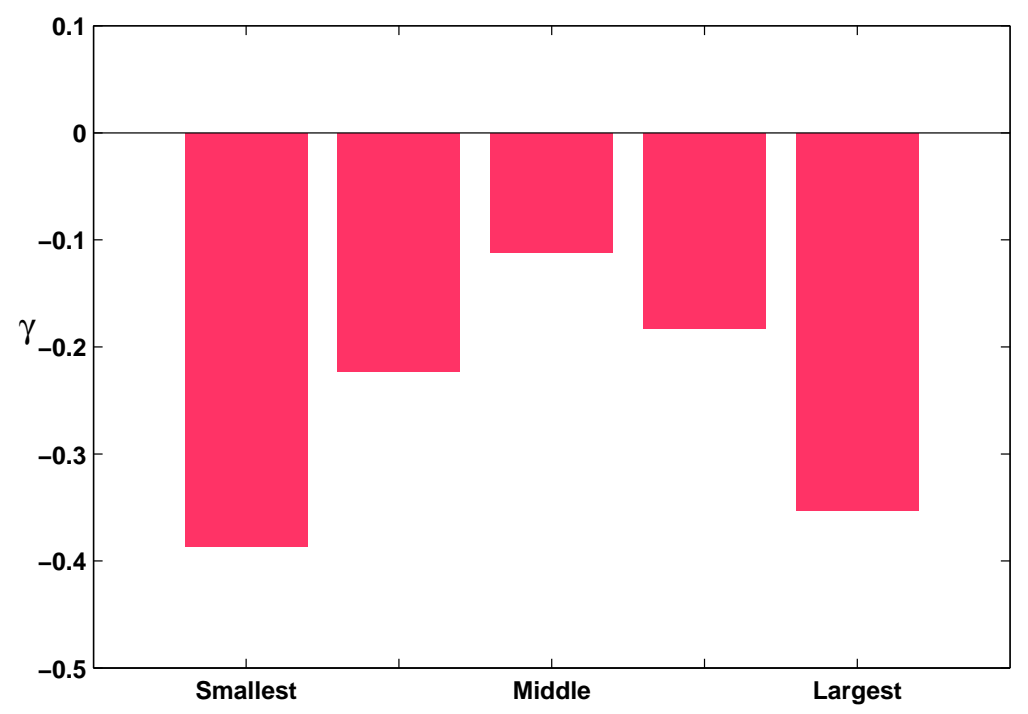

Note: This figure plots the estimates of group-specific slope coefficients. Firms are first divided into quintiles according to size; then firms of the same group are assumed to share the same slope, which differs from that of other groups.

Figure 6: By Debt Level: Responses to Uncertainty

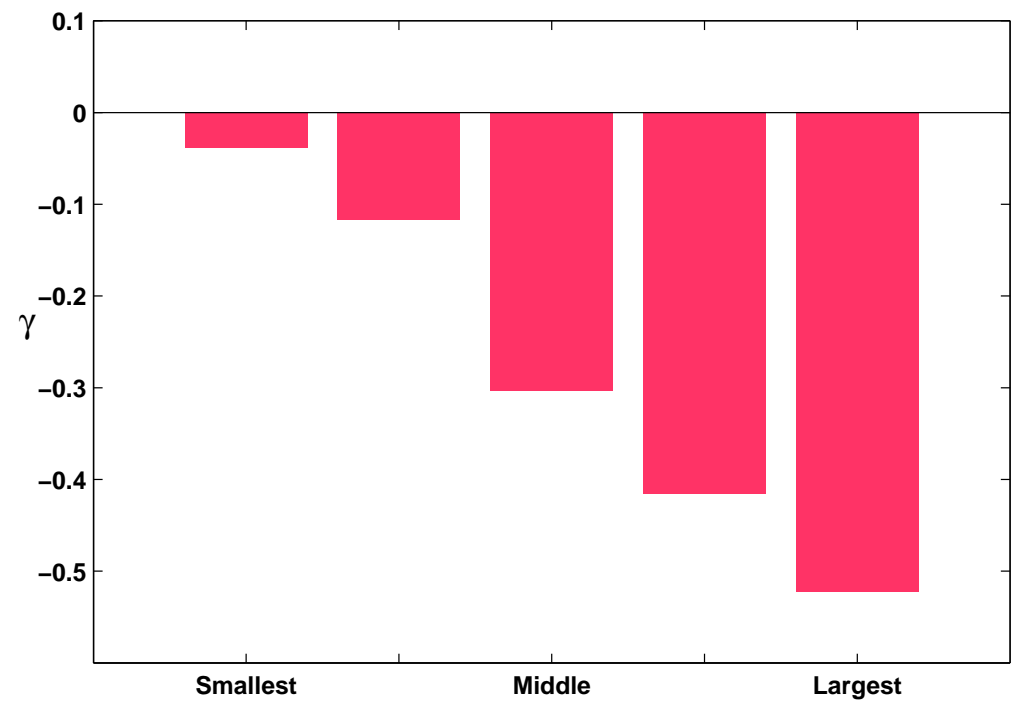

Note: This figure plots the estimates of group-specific slope coefficients. Firms are first divided into quintiles based on their liability-to-asset ratio; then firms of the same group are assumed to share the same slope, which differs from that of other groups. 
Figure 7: By Subindustry: Responses to Uncertainty

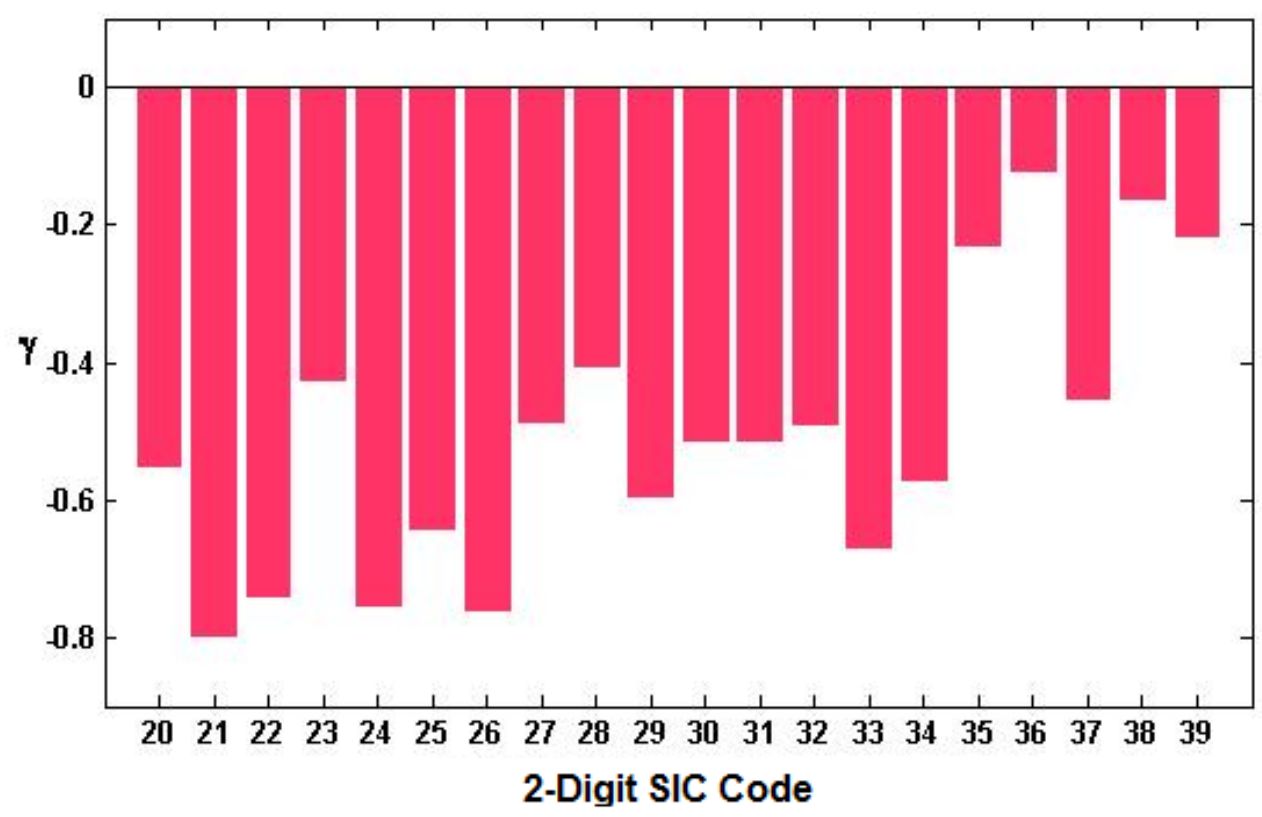

Note: This figure plots the estimates of group-specific slope coefficients. Firms are first divided into groups based on their 2-digit SIC code; firms of the same group are assumed to share the same slope, which differs from that of other groups. 
Figure 8: Responses to Uncertainty by Labour-to-Capital Ratios

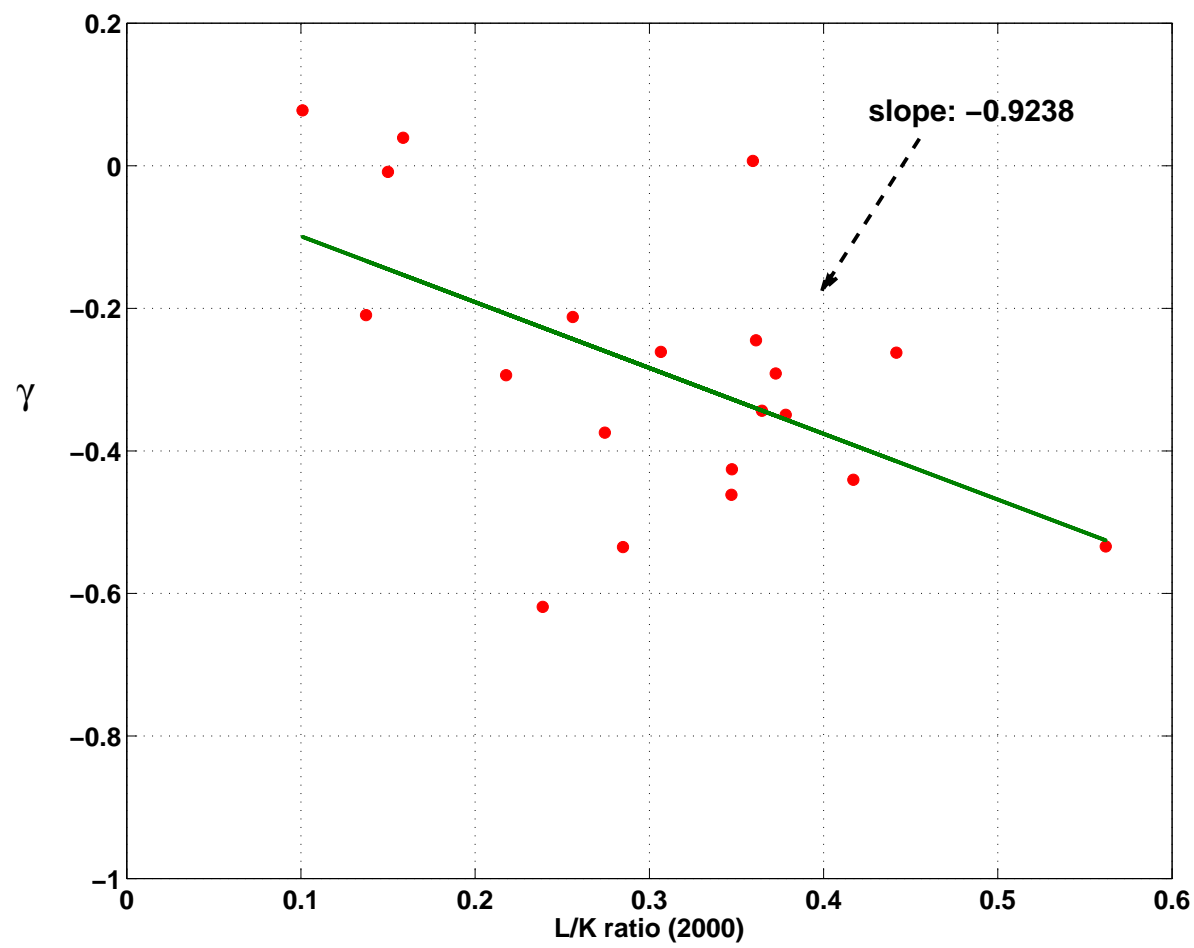

Note: This is a scatter plot of 2-digit subindustry-specific slope coefficient estimates versus labour-to-capital ratios of subindustries. The labour-to-capital ratios are measured in the year 2000. For demonstration purposes, we plot the fitted line from regressing subindustry-specific slope coefficient estimates on a constant and labour-to-capital ratios. 
Figure 9: Responses to Uncertainty by Standard Deviations of Labour-to-Capital Ratios

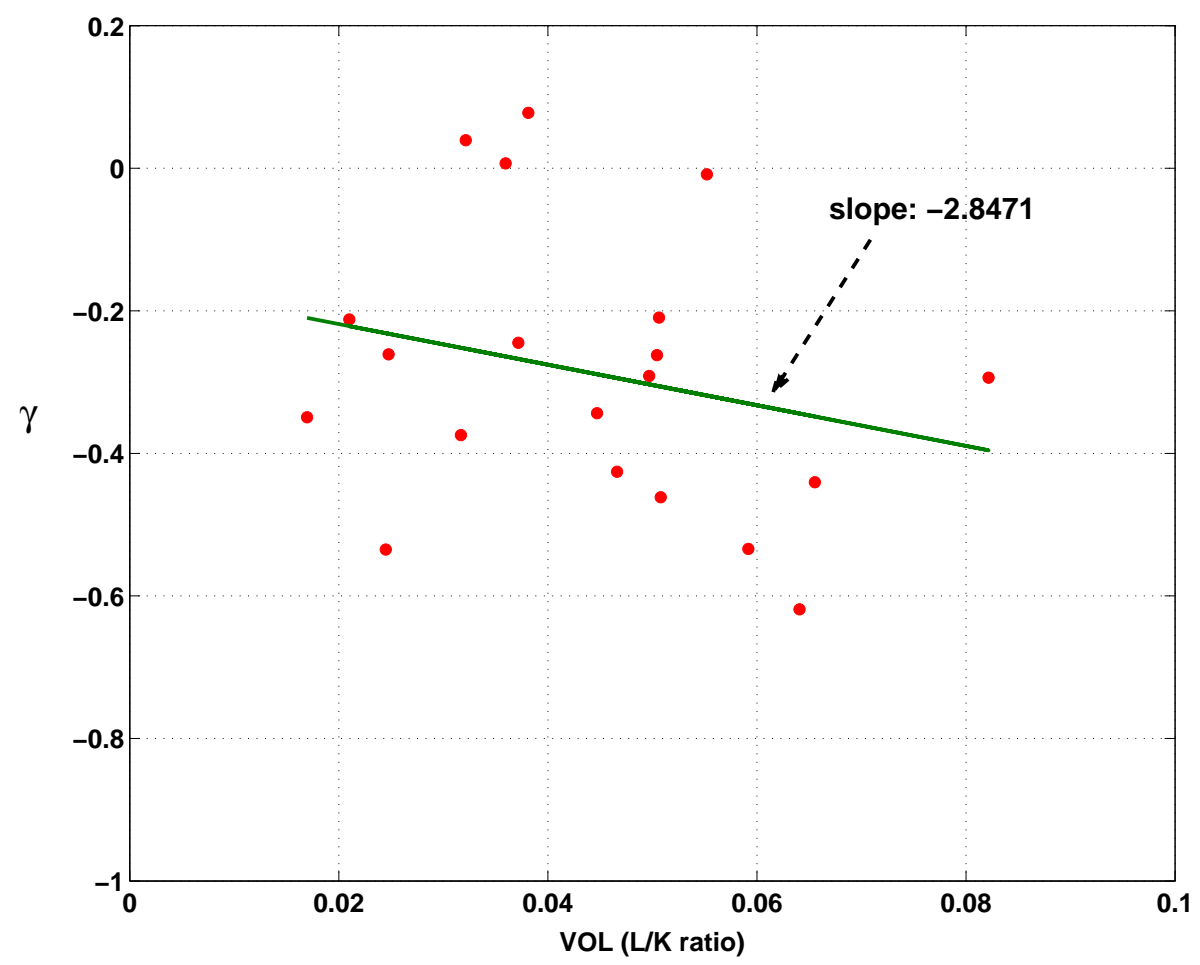

Note: This is a scatter plot of 2-digit subindustry-specific slope coefficient estimates versus standard deviations of labour-to-capital ratios of subindustries. The standard deviations of the labour-to-capital ratios are calculated from changes in the logarithm of the ratio. For demonstration purposes, we plot the fitted line from regressing subindustry-specific slope coefficient estimates on a constant and standard deviations of labour-to-capital ratios of subindustries. 
Figure 10: Five-Quarter Moving Average of Profit Uncertainty

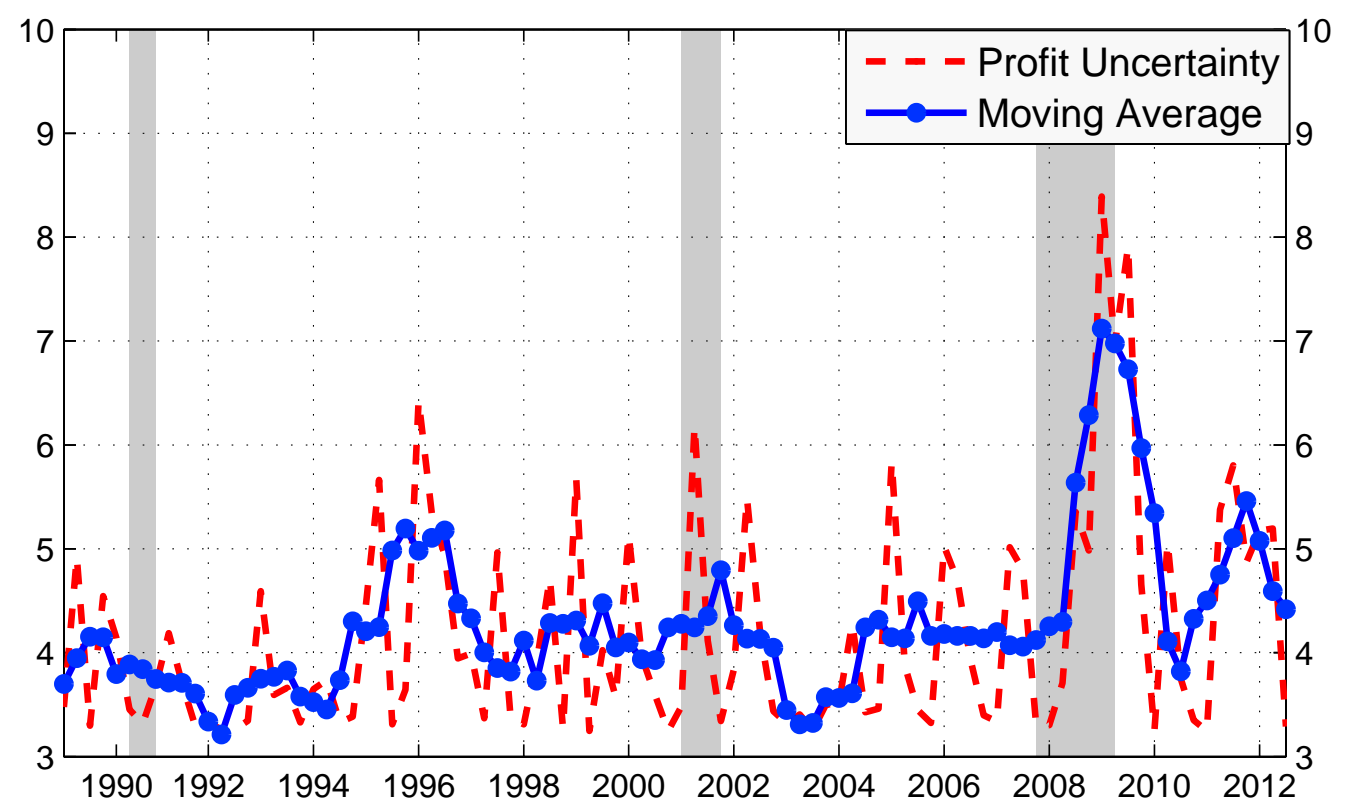

Note: Plotted above is a low-frequency dynamics of profit uncertainty calculated as moving averages of a five-quarter rolling window (in blue), along with the baseline profit uncertainty series (in red). 
Table 1: Order Determination of Panel-ARCH Model

\begin{tabular}{|l|cc|cc|cc|}
\hline & \multicolumn{2}{|c|}{$(1)$ Panel-ARCH$(1)$} & \multicolumn{2}{|c|}{ (2) Panel-ARCH(2) } & \multicolumn{2}{|c|}{ (3) Panel-GARCH $(1,1)$} \\
\hline & MLE & (s.e.) & MLE & (s.e.) & MLE & $($ s.e. $)$ \\
\hline$\alpha_{0}$ & $10.5412^{* * *}$ & $(4.7540)$ & $9.4208^{* *}$ & $(4.9186)$ & 4.7165 & $(8.9977)$ \\
\hline$\alpha_{1}$ & $0.2085^{* *}$ & $(0.1210)$ & $0.1816^{*}$ & $(0.1297)$ & 0.1658 & $(0.1312)$ \\
\hline$\alpha_{2}$ & & & 0.0506 & $(0.0819)$ & & \\
\hline$\beta_{1}$ & & & & & 0.3981 & $(0.6628)$ \\
\hline$\tau$ & $33.6701^{* * *}$ & $(0.2632)$ & $33.6701^{* * *}$ & $(0.2632)$ & $33.6701^{* * *}$ & $(0.2632)$ \\
\hline Log-likelihood & $-43,284.60$ & & $-43,284.34$ & $(0.47)$ & $-43,284.29$ & $(0.43)$ \\
\hline
\end{tabular}

Note: We report MLE and maximized log-likelihoods under various order specifications. Column (3) shows the results under the Panel-GARCH(1,1) model, where $\beta_{1}$ is the coefficient for lagged uncertainty. The asymptotic standard errors are obtained by approximating the second derivative of the Hessian matrix. Statistical significance of MLE is indicated by using asterisks $* /^{* *} / * * *$, representing the statistical significance at $90 \%, 95 \%$ and $99 \%$, respectively. The numbers in parentheses next to log-likelihoods are the p-values for a likelihood ratio test of one model against the Panel-ARCH(1) model, where the test statistic is twice the difference in log-likelihoods and is distributed chi-squared with degrees of freedom equal to the difference in the number of parameters. 


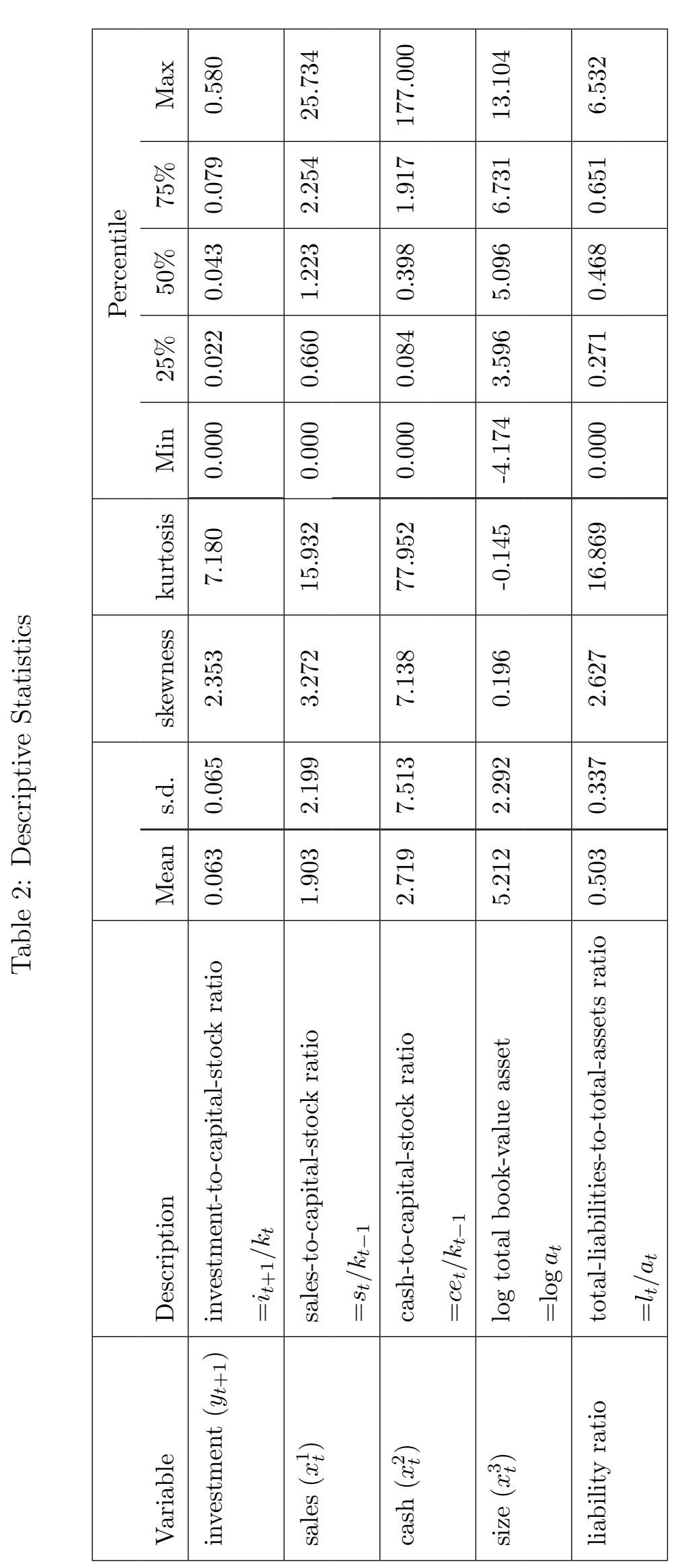

चี

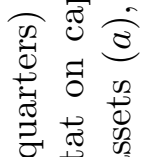

类

\&.

부유

穴 명

요워

궁요

$\infty$

$\rightarrow$ 过

둥으

$\forall$ 过

言莺志

음

$\stackrel{\Xi}{0}$

중

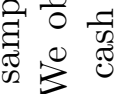

舟

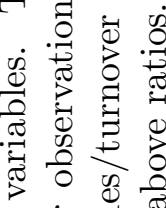

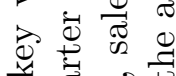

पै

की

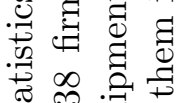
की 웜

즘

营䓴

\& ?

$\exists$ 잉

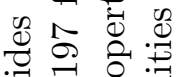

的范:

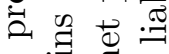

๑

需苛灾焉

刍节要

.

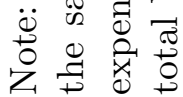




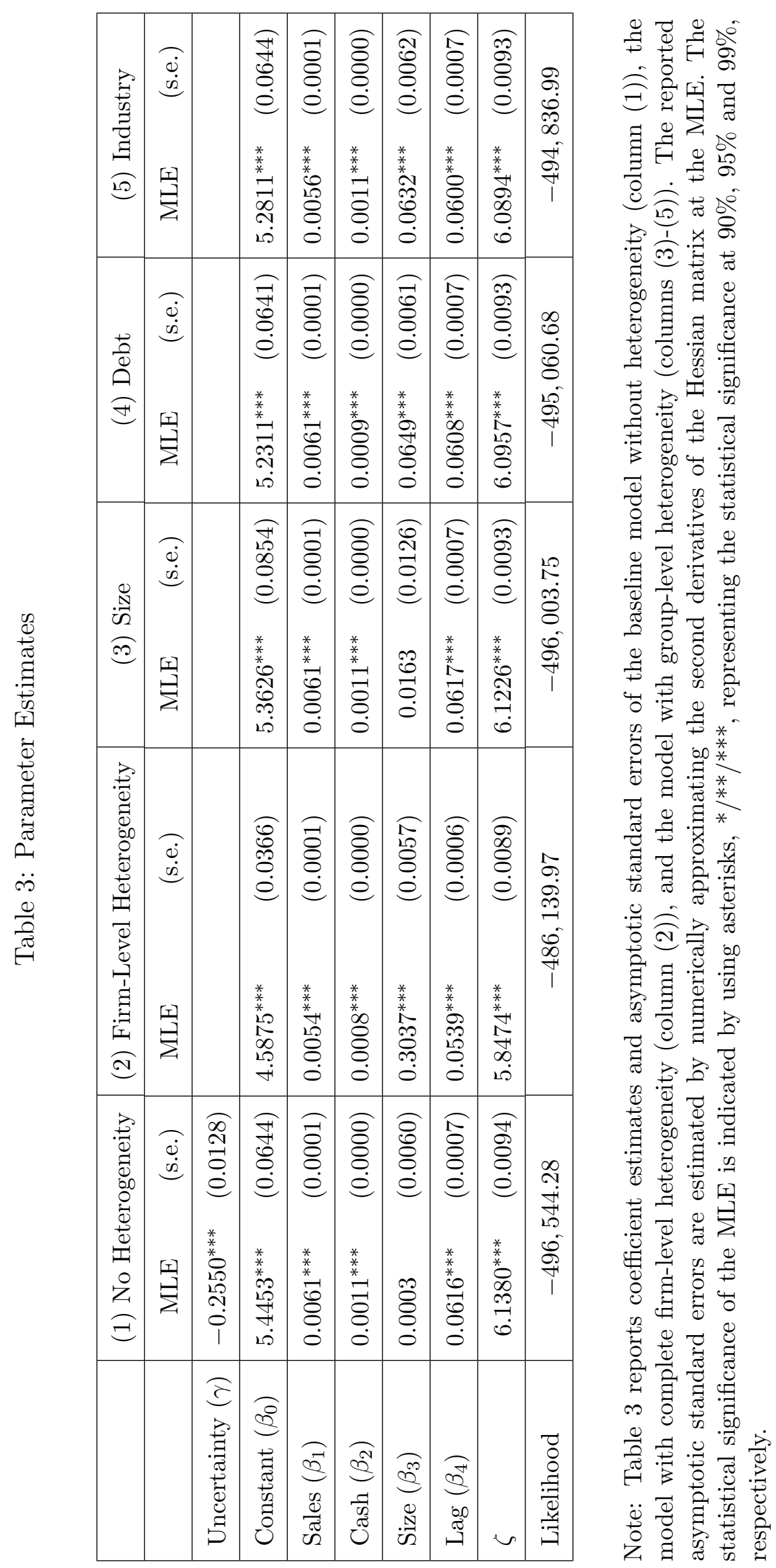


Table 4: Group Characteristics and Slope Coefficient Estimates

\begin{tabular}{|c|l|c|c|cc|}
\hline \multicolumn{2}{|c|}{ Panel 1: Size group description } & \multicolumn{2}{c|}{$\gamma$} \\
\hline size & Description & No. & Size & MLE & (s.e. $)$ \\
\hline 1 & Smallest & 1039 & 1.90 & $-0.3869^{* * *}$ & $(0.0171)$ \\
\hline 2 & & 1040 & 3.58 & $-0.2226^{* * *}$ & $(0.0150)$ \\
\hline 3 & & 1039 & 4.68 & $-0.1119^{* * *}$ & $(0.0143)$ \\
\hline 4 & & 1040 & 5.88 & $-0.1828^{* * *}$ & $(0.0143)$ \\
\hline 5 & Largest & 1039 & 8.03 & $-0.3533^{* * *}$ & $(0.0161)$ \\
\hline Panel 2: Debt group description & & & $\gamma$ \\
\hline leverage & Description & No. & Liability ratio & MLE & $($ s.e. $)$ \\
\hline 1 & Smallest & 1039 & 0.20 & $-0.0389^{* * *}$ & $(0.0141)$ \\
\hline 2 & & 1040 & 0.35 & $-0.1174^{* * *}$ & $(0.0139)$ \\
\hline 3 & & 1039 & 0.49 & $-0.3029^{* * *}$ & $(0.0139)$ \\
\hline 4 & & 1040 & 0.62 & $-0.4158^{* * *}$ & $(0.0142)$ \\
\hline 5 & Largest & 1039 & 0.94 & $-0.5226^{* * *}$ & $(0.0145)$ \\
\hline
\end{tabular}




\begin{tabular}{|c|l|c|c|c|cc|}
\hline \multicolumn{2}{|l}{ Panel 3: SIC2 group description } & No. & L/K & Vol & MLE & $($ s.e. $)$ \\
\hline SIC2 & Description & 264 & 0.38 & 0.02 & $-0.4682^{* * *}$ & $(0.0181)$ \\
\hline 20 & Food and kindred products & 10 & 0.24 & 0.06 & $-0.7422^{* * *}$ & $(0.0677)$ \\
\hline 21 & Tobacco products & 72 & 0.35 & 0.05 & $-0.5696^{* * *}$ & $(0.0313)$ \\
\hline 22 & Textile mill products & 99 & 0.14 & 0.05 & $-0.3263^{* * *}$ & $(0.0253)$ \\
\hline 23 & Apparel and other textile products & 70 & 0.56 & 0.06 & $-0.6503^{* * *}$ & $(0.0279)$ \\
\hline 24 & Lumber and wood products & 60 & 0.35 & 0.05 & $-0.5426^{* * *}$ & $(0.0289)$ \\
\hline 25 & Furniture and fixtures & 126 & 0.28 & 0.02 & $-0.6509^{* * *}$ & $(0.0231)$ \\
\hline 26 & Paper and allied products & 142 & 0.31 & 0.02 & $-0.3761^{* * *}$ & $(0.0228)$ \\
\hline 27 & Printing and publishing & 1020 & 0.26 & 0.02 & $-0.3350^{* * *}$ & $(0.0142)$ \\
\hline 28 & Chemicals and allied products & 82 & 0.27 & 0.03 & $-0.4950^{* * *}$ & $(0.0271)$ \\
\hline 29 & Petroleum and coal products & 147 & 0.37 & 0.05 & $-0.4061^{* * *}$ & $(0.0225)$ \\
\hline 30 & Rubber and miscellaneous plastic products & 26 & 0.22 & 0.08 & $-0.4112^{* * *}$ & $(0.0396)$ \\
\hline 31 & Leather and leather products & 64 & 0.44 & 0.05 & $-0.3786^{* * *}$ & $(0.0298)$ \\
\hline 32 & Stone, clay and glass products & 190 & 0.42 & 0.07 & $-0.5542^{* * *}$ & $(0.0204)$ \\
\hline 33 & Primary metal industries & 172 & 0.36 & 0.04 & $-0.4594^{* * *}$ & $(0.0210)$ \\
\hline 34 & Fabricated metal products & 682 & 0.15 & 0.06 & $-0.1248^{* * *}$ & $(0.0151)$ \\
\hline 35 & Industrial machinery and equipment & 889 & 0.10 & 0.04 & $-0.0432^{* * *}$ & $(0.0142)$ \\
\hline 36 & Electronic and other electric equipment & 240 & 0.36 & 0.04 & $-0.3640^{* * *}$ & $(0.0182)$ \\
\hline 37 & Transportation equipment & 720 & 0.16 & 0.03 & $-0.0810^{* * *}$ & $(0.0149)$ \\
\hline 38 & Instruments and related products & 122 & 0.36 & 0.04 & $-0.1074^{* * *}$ & $(0.0245)$ \\
\hline 39 & Miscellaneous manufacturing industries & & & & & \\
\hline
\end{tabular}

Note: Table 4 describes sample-split criteria as well as their main characteristics. Panels 1 and 2 report historical averages of book-valued assets (in logarithm), and total-liabilitiesto-total-assets ratio, respectively. Panel 3 reports the labour-to-capital ratio $(\mathrm{L} / \mathrm{K})$ in year 2000, as well as its historical volatility (Vol) from 1980 to 2001. The last column reports estimated group-specific coefficients ( $\gamma_{i}$ 's) and asymptotic standard errors of each group. The statistical significance of the MLE is indicated by using asterisks, * $/ * * / * * *$, representing the statistical significance at $90 \%, 95 \%$ and $99 \%$, respectively. 
Table 5: Baseline Model Estimation Results with Low-Frequency Movement of Uncertainty

\begin{tabular}{|l|cc|cc|cc|}
\hline & \multicolumn{2}{|c|}{$(1)$ Moving average } & \multicolumn{2}{|c|}{$(2)$ 1-year ahead } & \multicolumn{2}{c|}{$(3)$ VIX } \\
\hline & MLE & $($ s.e. $)$ & MLE & (s.e. $)$ & MLE & $($ s.e. $)$ \\
\hline Uncertainty $(\gamma)$ & $-0.1659^{* * *}$ & $(0.0156)$ & $-22.7138^{* * *}$ & $(1.0201)$ & $-3.1549^{* * *}$ & $(0.0551)$ \\
\hline Constant $\left(\beta_{0}\right)$ & $5.0941^{* * *}$ & $(0.0748)$ & $87.4140^{* * *}$ & $(3.7280)$ & $9.0189^{* * *}$ & $(0.0891)$ \\
\hline Sales $\left(\beta_{1}\right)$ & $0.0061^{* * *}$ & $(0.0001)$ & $0.0061^{* * *}$ & $(0.0001)$ & $0.0061^{* * *}$ & $(0.0001)$ \\
\hline Cash $\left(\beta_{2}\right)$ & $0.0011^{* * *}$ & $(0.0000)$ & $0.0011^{* * *}$ & $(0.0000)$ & $0.0011^{* * *}$ & $(0.0000)$ \\
\hline Size $\left(\beta_{3}\right)$ & -0.0026 & $(0.0060)$ & 0.0008 & $(0.0060)$ & $0.0208^{* * *}$ & $(0.0059)$ \\
\hline Lag $\left(\beta_{4}\right)$ & $0.0616^{* * *}$ & $(0.0007)$ & $0.0615^{* * *}$ & $(0.0007)$ & $0.0602^{* * *}$ & $(0.0007)$ \\
\hline$\zeta$ & $6.1421^{* * *}$ & $(0.0094)$ & $6.1367^{* * *}$ & $(0.0094)$ & $6.0973^{* * *}$ & $(0.0093)$ \\
\hline Likelihood & $-496,687.43$ & $-496,496.19$ & $-495,117.28$ \\
\hline
\end{tabular}

Note: Table 5 reports estimation results of our baseline model with long-run profit uncertainty. Column (1) is the result using moving averages of a five-quarter rolling window, as in equation (10). For comparison, we also present the results using a four-quarter-ahead profit uncertainty forecast generated recursively, and the VIX. The statistical significance of the MLE is indicated by asterisks, $* / * * * * *$, representing the statistical significance at $90 \%, 95 \%$ and $99 \%$, respectively. 


\section{A Panel-ARCH for Aggregate Profit Uncer- tainty}

Here we provide analytic formulas for the determinant and inverse of $J \times J$ variancecovariance matrix of forecasting errors, which facilitate the evaluation of the loglikelihood function. Then, we provide plots of the quarterly aggregate sales revenue index, the quarterly sales growth rate, and correlations between forecasting errors and weights at each quarter.

\section{A.1. Analytic formula}

Given (4), (5) and (6), $\Omega_{t+1} \equiv E\left[u_{t+1} u_{t+1}^{\prime} \mid \mathcal{F}_{t}\right]$ is a $J \times J$ symmetric variancecovariance matrix of forecasting errors provided by

$$
\Omega_{t+1}=\left[\begin{array}{cccc}
\frac{\sigma_{t+1}^{2}+\tau^{2}}{J^{2} \cdot w_{1, t}^{2}} & \frac{\sigma_{t+1}^{2}}{J^{2} w_{1, t} w_{2, t}} & \cdots & \frac{\sigma_{t+1}^{2}}{J^{2} w_{1, t} w_{J, t}} \\
\frac{\sigma_{t+1}^{2}}{J^{2} w_{2, t} w_{1, t}} & \frac{\sigma_{t+1}^{2}+\tau^{2}}{J^{2} \cdot w_{2, t}^{2}} & \cdots & \frac{\sigma_{t+1}^{2}}{J^{2} w_{2, t} w_{J, t}} \\
\vdots & \vdots & & \vdots \\
\frac{\sigma_{t+1}^{2}}{J^{2} w_{J, t} w_{1, t}} & \frac{\sigma_{t+1}^{2}}{J^{2} w_{J, t} w_{2, t}} & \cdots & \frac{\sigma_{t+1}^{2}+\tau^{2}}{J^{2} \cdot w_{J, t}^{2}}
\end{array}\right]
$$

where its determinant can be analytically calculated by

$$
\left|\Omega_{t+1}\right|=\tau^{2(J-1)} \cdot\left(\tau^{2}+J \sigma_{t+1}^{2}\right) \cdot\left(\prod_{j=1}^{J} \frac{1}{J^{2} w_{j, t}^{2}}\right)
$$

and its inverse matrix is summarized by denoting as $\Omega_{t+1}^{-1}(i, j)$ an $(i, j)^{t h}$ element in $\Omega_{t+1}^{-1}$,

$$
\Omega_{t+1}^{-1}(i, j)=\left\{\begin{array}{cc}
\frac{J^{2} w_{i, t}^{2} \cdot\left(\tau^{2}+(J-1) \cdot \sigma_{t+1}^{2}\right)}{\tau^{2} \cdot\left(\tau^{2}+J \cdot \sigma_{t+1}^{2}\right)} & \text { for } j=i \\
-\frac{J^{2} w_{i, t} w_{j, t} \cdot \sigma_{t+1}^{2}}{\tau^{2} \cdot\left(\tau^{2}+J \cdot \sigma_{t+1}^{2}\right)} & \text { for } j \neq i
\end{array}\right.
$$

Then, we can obtain the suggested closed-form log-likelihood function by plugging the above analytic formula into the general log-likelihood function for jointly modelling $J$ subindustries. 


\section{A.2. Aggregate sales revenue index and its growth rate}

Figure A1 plots the quarterly sales revenue index from equation (1) after setting the index level in 1981Q1=100; the gross sales revenue $\left(S_{t}\right)$ increases over time with strong seasonality. After controlling for the observed seasonality in $S_{t}$ through seasonal dummies, we calculate the quarterly sales growth rate as plotted in Figure A2. The sales growth is relatively low during recessions, but overall very volatile, with volatility clustered similar to the behaviour of the stock return.

Figure A1: Aggregate Sales Index

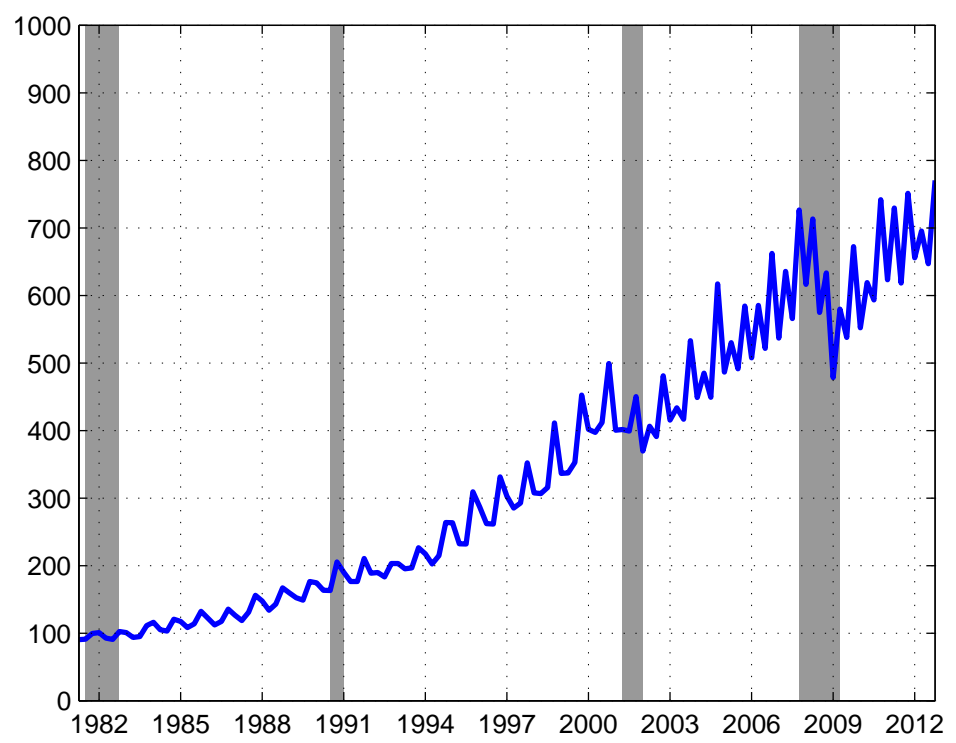

Note: This figure plots the aggregate sales revenue index from 1981Q1 to 2012Q4. The series is normalized by setting the initial level equal to 100 .

We calculate the correlation coefficients between forecasting errors $\left(u_{j, t+1}\right)$ and sales shares $\left(w_{j, t}\right)$ across subindustries for each quarter, and plot the correlation coefficients in Figure A3. Among 123 quarters in the sample, there are ten quarters with positive correlations. In all remaining quarters, forecasting errors and sales shares of subindustries are negatively related, suggesting that the restriction in (6) is consistent with the underlying relationship between $u_{j, t+1}$ and $w_{j, t}$ 's in the data. 
Figure A2: Quarterly Sales Growth Rate

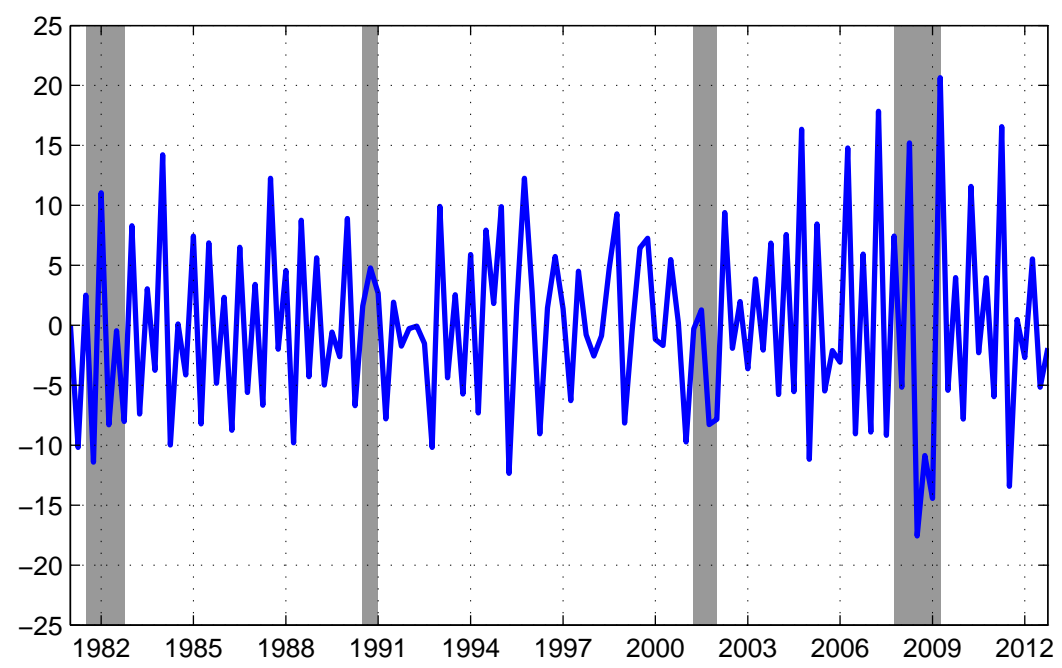

Note: This figure plots the deseasonalized quarterly growth rate of the aggregate sales index. Deseasonalization is done by regressing the growth rate on seasonal dummies.

Figure A3: Correlation between Size of Forecasting Errors and Sales Shares

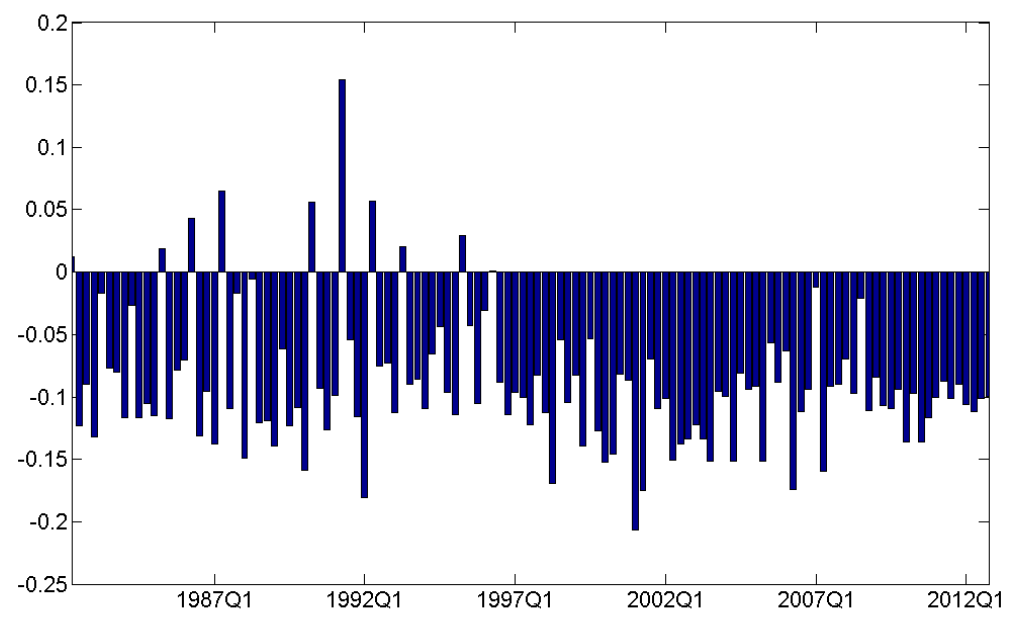

Note: This figure shows the correlation coefficients between the absolute values of forecasting errors from the sales growth forecasting equation (3) and the previous quarter's sales shares during the sample period. Each period, we have forecasting errors of 67 industries $\left(u_{j, t+1}\right)$ and their sales series from the previous quarter $\left(w_{j, t}\right)$, with which we compute correlation coefficients. 


\section{B Investment Forecasting Model}

\section{Data}

The manufacturing firm panel data are taken from the combined quarterly Compustat North America industrial file, from which we obtain capital expenditure (investment, $i_{t}$ ), net property plant and equipment (capital, $k_{t}$ ), total book-valued assets (size, $a_{t}$ ), sales/turnover (sales, $s_{t}$ ), cash and cash equivalents (cash, $c e_{t}$ ), and total liabilities (liability, $l_{t}$ ). All variables except the capital expenditure are reported on a quarterly basis; for example, capital is the book value of capital stocks for the reported quarter, and sales refers to the gross revenue from goods sold during the quarter. The capital expenditure, however, is reported as a year-to-date item, which we transform to be a quarterly value by subtracting the previous period's (year-to-date) amount from that of the current period.

Given the unbalanced panel data spanning from 1989Q4 to 2012Q4, we first delete observations with missing variables, non-positive capital and size, negative sales and/or cash, and with liabilities likely to indicate highly distressed firms. We also delete observations with capital expenditures greater than $15 \%$ of book value assets, following Leahy and Whited (1996), and observations either below $2.5 \%$ or above $97.5 \%$ in each quarter for selected variables: $i_{t+1} / k_{t}, s_{t} / k_{t-1}, c e_{t} / k_{t-1}$ and $l_{t} / a_{t}$. Lastly, we remove 1,981 firms with less than 12 quarterly observations during the sample periods, corresponding to 11,384 firm-quarter observations.

Due to different fiscal-year conventions across firms, we create quarterly observations based on their reporting dates. To normalize units, we divide the capital expenditure $\left(i_{t+1}\right)$, sales $\left(s_{t}\right)$, and cash $\left(c e_{t}\right)$ by the beginning-period capital stocks. Lastly, we adjust the total book value assets $\left(a_{t}\right)$ in 2005Q3 U.S. dollars.

\section{Estimation}

Given moderate non-linearity, the numerical MLE of the investment forecasting equation is relatively straightforward, except for the large dimension in firm-specific coefficients $\left(\gamma_{i}\right)$ that arises when we allow for firm-level heterogeneity. In this case, the model is estimated with the aid of the Zigzag algorithm, where we iterate be- 
tween a linear projection of $\gamma_{i}$ 's and the numerical MLE recursively until convergence.

\section{Further Robustness Checks}

\section{Formal Test of Group-Level Heterogeneity}

To evaluate the findings in Section 4.3 of the paper more formally, we rewrite groupspecific slope coefficients $\gamma_{i}$ as a function of firm characteristics of interest. In other words, we impose the following restriction on $\gamma_{i}$ :

$$
\gamma_{i}=\gamma_{0}+\delta \cdot X_{i},
$$

where $X_{i}$ is, for instance, a size, a leverage ratio or a labour-to-capital ratio (or its volatility) of firm $i$. Under this particular model specification, slope coefficient estimates $(\delta)$ provide a natural way of testing imposed restrictions. Note that this particular reparameterization will not fully capture the inverse U relation found between the firm size and $\gamma_{i}$ 's. Hence, our intention is to test the significance of a linear trend only, which can be limiting, especially in the case of grouping by size. Lastly, we use a labour-to-capital ratio or the historical standard deviation of a subindustry that firm $i$ belongs to, since the labour-to-capital ratio is not available at the firm level.

Table C1 reports estimates from restricted models. As seen from the point estimates of $\delta$, the results corroborate our previous findings of the heterogeneity with respect to different firm characteristics. For example, in column (2) of Table $\mathrm{C} 1$, the significantly negative point estimate of $\delta$ indicates that a high liability ratio debilitates the way firms cope with profit uncertainty. 


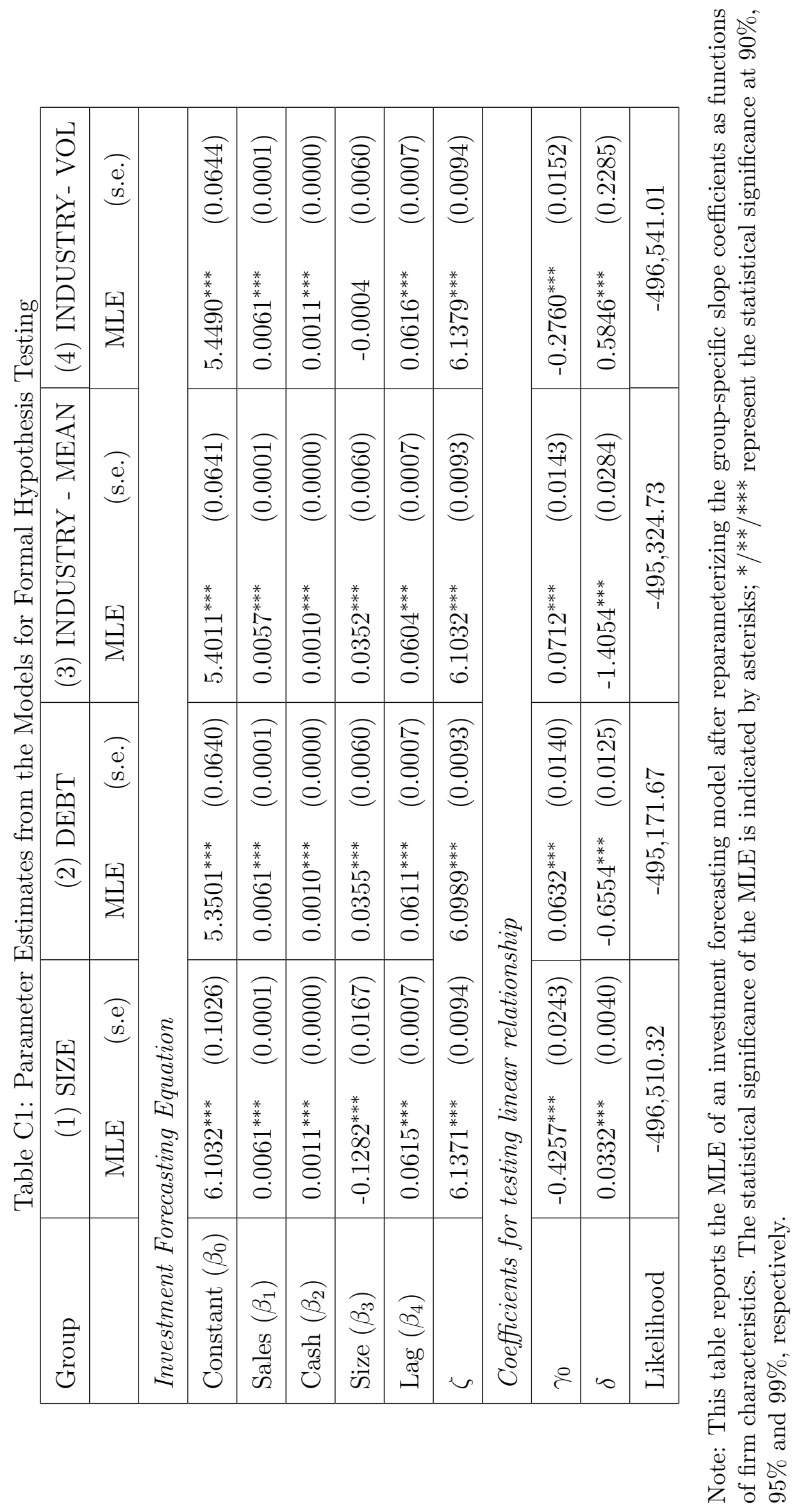

